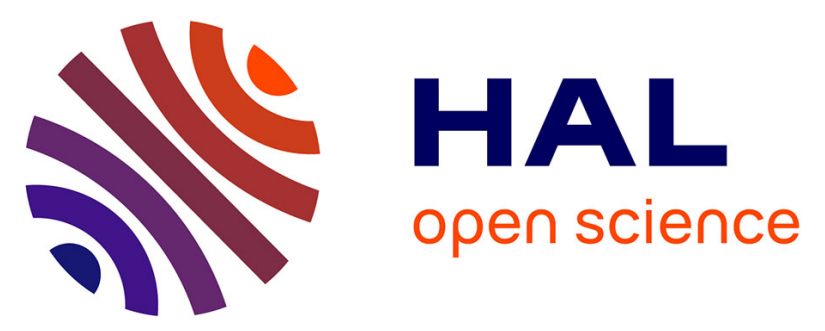

\title{
Proteome characterization in various biological fluids of Trypanosoma brucei gambiense-infected subjects
}

\author{
Julien Bonnet, Camille Garcia, Thibaut Léger, Marie-Pauline Couquet, \\ Philippe Vignoles, Gedeao Vatunga, Joseph Ndung'U, Clotilde Boudot, Sylvie \\ Bisser, Bertrand Courtioux
}

\section{To cite this version:}

Julien Bonnet, Camille Garcia, Thibaut Léger, Marie-Pauline Couquet, Philippe Vignoles, et al.. Proteome characterization in various biological fluids of Trypanosoma brucei gambiense-infected subjects. Journal of Proteomics, 2018, 10.1016/j.jprot.2018.11.005 . hal-01936184

\section{HAL Id: hal-01936184 \\ https://hal-unilim.archives-ouvertes.fr/hal-01936184}

Submitted on 22 Oct 2021

HAL is a multi-disciplinary open access archive for the deposit and dissemination of scientific research documents, whether they are published or not. The documents may come from teaching and research institutions in France or abroad, or from public or private research centers.
L'archive ouverte pluridisciplinaire HAL, est destinée au dépôt et à la diffusion de documents scientifiques de niveau recherche, publiés ou non, émanant des établissements d'enseignement et de recherche français ou étrangers, des laboratoires publics ou privés.

\section{(ㄷ)(1) $\$$}

Distributed under a Creative Commons Attribution - NonCommerciall 4.0 International 


\section{Proteome characterization in various biological fluids of Trypanosoma}

\section{brucei gambiense-infected subjects}

4 Julien Bonnet $^{1 *}$, Camille Garcia ${ }^{2}$, Thibaut Leger $^{2}$, Marie-Pauline Couquet ${ }^{1}$, Philippe Vignoles ${ }^{1}$,

5 Vatunga Gedeao ${ }^{3}$, Joseph Ndung' $\mathbf{u}^{4}$, Clotilde Boudot ${ }^{1}$, Sylvie Bisser ${ }^{1,5}$, Bertrand Courtioux ${ }^{1}$.

6

71 Institute of Neuroepidemiology and Tropical Neurology, School of Medicine, CNRS FR 3503

8 GEIST, University of Limoges, INSERM UMR 1094 Tropical Neuroepidemiology, Limoges,

9 France.

102 Jacques Monod Institute, Proteomics Facility, University Paris Diderot Sorbonne Paris Cité,

11 Paris, France.

123 Instituto de Combate e controlo das Tripanossomiases (ICCT), Luanda, Angola.

134 Foundation for Innovative New Diagnostics (FIND), Geneva, Switzerland.

145 Pasteur Institute in French Guiana, 23 Boulevard Pasteur, 973006 Cayenne Cedex, French

15 Guiana.

16 Email: julien.bonnet@unilim.fr, camille.garcia@ijm.fr, thibaut.leger@ijm.fr,

17 mariepauline.couquet@gmail.com,_philippe.vignoles@unilim.fr,_vmlgedeao@live.com,

18 joseph.ndungu@finddx.org,_ boudot.clotilde@gmail.com,_ sbisser@pasteur-cayenne.fr,

19 bertrand.courtioux@unilim.fr

20

$21 *$ Corresponding author

22 E-mail : julien.bonnet@unilim.fr

23 


\section{Abstract}

25 Human African trypanosomiasis (HAT) is a neglected tropical disease that is endemic in sub-

26 Saharan Africa. Control of the disease has been recently improved by better screening and

27 treatment strategies, and the disease is on the WHO list of possible elimination. However, some

28 physiopathological aspects of the disease transmission and progression remain unclear. We

29 propose a new proteomic approach to identify new targets and thus possible new biomarkers of

30 the disease. We also focused our attention on fluids classically associated with HAT (serum and

31 cerebrospinal fluid (CSF)) and on the more easily accessible biological fluids urine and saliva.

32 Liquid chromatography-tandem mass spectrometry (LC-MS/MS) established the proteomic

33 profile of patients with early and late stage disease. The serum, CSF, urine and saliva of 3

34 uninfected controls, 3 early stage patients and 4 late stage patients were analyzed.

35 Among proteins identified, in CSF, urine and saliva, respectively, 37, 8 and 24 proteins were

36 differentially expressed and showed particular interest with regards to their function. The most

37 promising proteins (Neogenin, Neuroserpin, secretogranin 2 in CSF; moesin in urine and

38 intelectin 2 in saliva) were quantified by enzyme-linked immunosorbent assay in a confirmatory

39 cohort of 14 uninfected controls, 23 patients with early stage disease and 43 patients with late

40 stage disease. The potential of two proteins, neuroserpin and moesin, with the latter present in

41 urine, were further characterized.

42 Our results showed the potential of proteomic analysis to discover new biomarkers and provide

43 the basis of the establishment of a new proteomic catalogue applied to HAT-infected subjects and 44 controls.

46 Key words: Sleeping sickness, biological fluids, proteomic 


\section{Introduction}

48 Human African trypanosomiasis (HAT), also known as sleeping sickness, is a parasitic disease,

49 caused by subspecies of Trypanosoma brucei, that mainly affects poor and rural communities in 50 more than 20 sub-Saharan African countries [1]. HAT is one of 20 neglected tropical diseases 51 (NTDs) recognized by the World Health Organization (WHO) [2], and it is estimated that 55 52 million people live at risk of contracting HAT infection [3]. In the human population, T. $b$. 53 gambiense is responsible for more than $98 \%$ of HAT cases in central and western Africa, T. $b$. 54 rhodesiense is responsible of the remaining $2 \%$ of cases, which is prevalent in eastern and 55 southern Africa. However, since 2009, fewer than 10,000 cases have been reported each year [3]$56[5]$.

57 Trypanosomes are inoculated into human hosts by tsetse fly vectors; the trypanosomes then 58 multiply and spread into the blood and lymphatic system. T. $b$. gambiense causes a chronic form 59 of disease that develops over months to years in two stages. The first stage (S1), or 60 hemolymphatic stage, is generally characterized by intermittent fever, lymphadenopathy, 61 hepatosplenomegaly and headaches [5]. These symptoms are discrete and nonspecific for HAT. 62 After a variable duration of time, trypanosomes cross the blood-brain barrier and reach the 63 central nervous system (CNS); this stage is called the second stage (S2) or nervous stage. S2 is 64 characterized by neurological signs and symptoms and usually leads to death if untreated [6], [7].

65 Currently, several tests adapted to the field are used to diagnose HAT, the card agglutination test 66 for trypanosomiasis (CATT) is still the most widely used screening test although single-format 67 rapid diagnostic tests have been recently validated [8]. When the screening test is positive, the 68 disease must be confirmed by demonstrating the presence of the parasite by microscopy. The 69 tests used include blood concentration techniques such as the capillary tube centrifugation (CTC) 
and mini anion exchange centrifugation technique (mAECT) [9], [10] or examination of lymph

71 node aspirates when lymph nodes are swollen. Once diagnosis of the disease is established by

72 one or more of these tests, it is important to stage the disease to guide treatment regimen. The staging criteria defined by the WHO are the absence of trypanosomes in the cerebrospinal fluid (CSF), and fewer than 5 white blood cells (WBC)/ $\mu \mathrm{L}$ CSF for patients with S1 disease, and the presence of trypanosomes in the CSF and/or more than $6 \mathrm{WBC} / \mu \mathrm{L}$ CSF for patients with $\mathrm{S} 2$ disease. These staging criteria are not always easy to use in settings where the disease occurs; microscopy is not a sensitive enough technique to reliably detect the parasite in the CSF, and the CSF WBC count is not specific for HAT [11]. Without the right diagnosis, S1 disease may progress to S2 disease, and patients may not get the correct treatment. Patients with S1 T. $b$. gambiense HAT are treated with pentamidine. S2 patients require treatments that can cross the blood-brain barrier. Trypanosoma b. gambiense S2 infection can be treated with a nifurtimox-eflornithine combination therapy (NECT), but this treatment is given by infusion which is invasive and difficult to perform in some areas [12]. For T. b. rhodesiense, melarsoprol is the only treatment available [3]. A new easy-to-use treatment, named Fexinidazole, is expected to be available in 2018. However, this treatment, even if it appears to be active in both stages of the disease, is proposed as an alternative to NECT, therefore for the treatment of S2. The use of pentamidine to treat S1 remains the current course of action [13]. Even if we can hope for the

88 arrival of a molecule that will allow us to treat both stages of the disease, greatly facilitating the 89 diagnostic and therapeutic plan of patients, the determination of the stage of the disease is still 90 necessary at this time. 
92 The composition of the proteome of different biological fluids change with disease progression

93 and may lead to the generation of biomarkers that could be used in diagnosing and staging of the

94 disease [14]. Currently, proteome mapping is experiencing substantial growth owing to very

95 high-resolution techniques such as liquid chromatography-tandem mass spectrometry (LC-

96 MS/MS). Tandem mass spectrometry analysis allows a large proteome screen compared with

97 more specific techniques such as enzyme-linked immunosorbent assay (ELISA), immunoblotting

98 techniques and others that focus only on a single protein or small part of the proteome. The data

99 obtained with this technique, compared with the current human protein database, allow

100 identification and categorization of the proteins present in a biological sample with extensive

101 proteome coverage. Studies using LC-MS/MS have already discovered new biomarkers in many

102 diseases, such as Duchenne muscular dystrophy, amyotrophic lateral sclerosis, oral cavity

103 squamous cell carcinoma and breast cancer [15]-[18]. To enable the discovery of new

104 biomarkers from the proteome of biological fluids, it is important to characterize the entire

105 proteomes of both healthy and infected individuals. In this study, the serum, CSF, saliva and

106 urine proteomes obtained in patients with S1 and S2 T. b. gambiense HAT were compared with

107 uninfected controls. Using a high-resolution mass spectrometer coupled to a nano-ultra-

108 performance liquid chromatography (UPLC) system, several proteins with variable abundance

109 levels between the different groups were revealed by label-free protein quantification analysis.

110 The objective of this study was to characterize the proteome of serum, CSF, urine and saliva from

111 patients with $T$. b. gambiense HAT and to identify biological markers that could be used in

112 disease diagnosis and staging. 


\section{Material and Methods}

\section{Subjects and sample collection}

115 The samples used in this study were collected during a prospective cohort study carried out 116 between 2009 and 2011 in three provinces in Angola: Bengo, Uíge and Kwanza Norte. The study 117 enrolled 247 Angolan subjects: 67 were classified as S1 patients, 161 as S2 patients, and 19 as

118 controls. All patients were designated HAT positive by CATT (with or without titration), and 119 trypanosomes demonstration by microscopy in the blood or in lymph node aspiration. Patients in 120 the cohort had T. b. gambiense HAT, and were staged before treatment. Patients with no 121 trypanosomes in the CSF and normal $\mathrm{WBC}$ counts $(\leq 5 \mathrm{WBC} / \mu \mathrm{L} \mathrm{CSF})$ were classified as $\mathrm{S} 1$

122 patients. Patients with a WBC counts of more than $5 \mathrm{WBC} / \mu \mathrm{L}$ CSF and/or presence of 123 trypanosomes in the CSF were classified as S2 patients. Controls were subjects who had tested 124 positive for HAT by CATT but without parasite confirmation in blood, lymph node or CSF and 125 without development of the disease during the whole follow-up period. Every subject was 126 examined clinically and submitted to a questionnaire to document clinical and neurological 127 characteristics. Neurological data included an index of depression, measured with the Hamilton 128 rating scale [19], and the sleep and psychiatric disturbance using the Mini-International 129 neuropsychiatric interview [20]. Main co-infections were excluded in the field by microscopy for 130 common parasitic co-infections (blood smear for malaria, CTC for detection of filariasis, 131 examination of a urine sediment for schistosomiasis when urine was positive for blood).

132 Retrospectively, samples were tested for HIV and syphilis, and all positive samples were 133 excluded from the study.

134 For both controls and patients, samples of $5 \mathrm{~mL}$ of serum, $4 \mathrm{~mL}$ of CSF, $2 \mathrm{~mL}$ of urine and $2 \mathrm{~mL}$ 135 of saliva were stored in liquid nitrogen, transported to Limoges (France), in dry tanks and further 
136 stored at $-80^{\circ} \mathrm{C}$. Samples used for this study were carefully selected among the cohort and

137 common co-infections were excluded.

\section{Ethics statement}

139 Ethical clearance was obtained from the Direccao National de Saude Publica, Ministerio da

140 Saude, Angola. Written informed consent was obtained from all participants and, for participants

141 below 18 years of age, from their parents or guardians, prior to enrolment. Any individual who

142 declined to participate was managed according to the standard procedures of the national HAT

143 control program.

\section{Study design}

145 Potential biomarkers were first screened in serum, CSF, urine and saliva on a small population of

146 controls and patients by mass spectrometry and, second, the most promising biomarkers were

147 then quantified on a larger cohort.

148 The screening cohort $(\mathrm{n}=10)$

149 LC-MS/MS analysis was done on uninfected controls $(n=3)$, S1 patients $(n=3)$ and S2 patients

$150 \quad(n=4)$. Only adult males were included to avoid variations of the proteome linked to the

151 expression of hormonal proteins.

152 Quantitative analysis of the validation cohort by ELISA $(n=80)$

153 Protein quantification was done on samples collected after inclusion for controls $(\mathrm{n}=14), \mathrm{S} 1$

154 patients $(n=23)$ and S2 patients $(n=43)$. All samples used for the LC-MS/MS analysis were 155 included for protein quantification.

156 Two analyses were done: the first to identify among the detected proteins those that differentiated 157 controls from patients with HAT $(n=66)$; the second to verify whether these proteins could 
158 discriminate S1 from S2 patients. The most promising proteins that could differentiate S1 and S2

159 patients were also quantified at 12 months follow-up to verify their potential to be a marker of 160 cure.

\section{LC-MS/MS analysis}

\section{Sample preparation}

163 Serum, CSF, saliva and urine samples were used in this analysis. A preliminary step of depletion

164 has been carried out to reduce the quantity of predominant proteins ( $\alpha 1$-Acid Glycoprotein, $\alpha 1$ -

165 Antitrypsin, alpha 2-Macroglobulin, Albumin, Apolipoprotein A-I, Apolipoprotein A-II, 166 Fibrinogen, Haptoglobin, IgA, IgG, IgM, Transferrin) in these biological fluids. The dynamic 167 range of protein concentrations in different human fluids can be large. Without this step, the high 168 abundance of these predominant proteins would overwhelm the data obtained for the analysis of 169 low abundance proteins. Samples containing $10 \mu \mathrm{g}$ of protein, after depletion (Proteome purify 17012 Human, R\&D Systems ${ }^{\circledR}$ ) and concentration (AMICON ULTRA, Merck Millipore ${ }^{\circledR}$ ), were 171 adjusted to $120 \mu \mathrm{L}$ of the reaction mixture containing $4 \mathrm{M}$ urea, $1.5 \mathrm{M}$ thiourea and $50 \mathrm{mM}$ tris-

$172 \mathrm{HCl} \mathrm{pH} \mathrm{8.3.} \mathrm{Proteins} \mathrm{were} \mathrm{reduced} \mathrm{with} 10 \mathrm{mM}$ dithiothreitol for $30 \mathrm{~min}$ and then alkylated with $17355 \mathrm{mM}$ iodoacetamide for $20 \mathrm{~min}$. Alkylated proteins were first digested with $500 \mathrm{ng}$ of 174 endopeptidase lys-C (Wako®) for $3 \mathrm{~h}$ at room temperature (RT). Then the mixture was diluted with 3 volumes of MilliQ-water and treated with $500 \mathrm{ng}$ of trypsin (Sequence Grade Trypsin,

176 Promega ${ }^{\circledR)}$ for $16 \mathrm{~h}$ at RT. Enzymatic activity was stopped by addition of formic acid to a final 177 concentration of $3 \%$. Samples were stored at $-20{ }^{\circ} \mathrm{C}$ until use. In the case of saliva, a preliminary 178 acetone $(100 \%)$ precipitation step at $-20{ }^{\circ} \mathrm{C}$ was carried out. The saliva and urine samples were

179 not depleted to avoid a loss of proteins as the sample volume was low (1.5mL).

\section{Sample analysis}


181 Peptide mixtures (10 corresponding to patients) were analyzed by a Q-Exactive Plus coupled to a

182 Nano-LC Proxeon 1000 equipped with an easy spray ion source (all from Thermo Scientific).

183 Peptides were separated by chromatography with the following parameters: Acclaim PepMap100

184 C18 pre-column $(2 \mathrm{~cm}, 75 \mu \mathrm{m}$ i.d., $3 \mu \mathrm{m}, 100 \AA$ A $)$, Pepmap-RSLC Proxeon C18 column $(50 \mathrm{~cm}$,

$18575 \mu \mathrm{m}$ i.d., $2 \mu \mathrm{m}, 100 \AA$ ), $300 \mathrm{~nL} / \mathrm{min}$ flow rate, gradient from $95 \%$ solvent A (water, $0.1 \%$

186 formic acid) to $35 \%$ solvent $\mathrm{B}$ (100\% acetonitrile, $0.1 \%$ formic acid) over a period of 98

187 minutes, followed by a column regeneration for $23 \mathrm{~min}$, giving a total run time of 2 hours.

188 Peptides were analyzed in the Orbitrap cell, in full ion scan mode, at a resolution of 70,000 (at

$189 \mathrm{~m} / \mathrm{z} 200$ ), with a mass range of $\mathrm{m} / \mathrm{z}, 375-1500$ and an AGC target of $3 \times 10^{6}$. Fragments were

190 obtained by high collision-induced dissociation (HCD) activation with a collisional energy of

$19130 \%$, and a quadrupole isolation window of 1.4 Da. MS/MS data were acquired in the Orbitrap

192 cell in a Top20 mode, at a resolution of 17,500, with an AGC target of $2 \times 10^{5}$, with a dynamic

193 exclusion of 30 seconds. The most intense precursor ions were acquired first by MS/MS. Peptides

194 with unassigned charge states or monocharged were excluded from the MS/MS acquisition. The

195 maximum ion accumulation time was set to $50 \mathrm{~ms}$ for MS acquisition and $45 \mathrm{~ms}$ for MS/MS

196 acquisition.

\section{Peptide and protein identification}

198 For the peptide and protein identification step, all MS and MS/MS data were processed with

199 Proteome Discoverer software (Thermo Scientific, version 2.1) and with Mascot search engine

200 (Matrix Science, version 5.1). The mass tolerance was set to $6 \mathrm{ppm}$ for precursor ions and 0.02

201 Da for fragments. The maximum number of missed cleavages was limited to two for the trypsin

202 protease. The SwissProt database with the Homo sapiens and the T. . gambiense taxonomies was

203 used for the MS/MS identification step. The following variable modifications (2 maximum per

204 peptide) were allowed: oxidation (M) and carbamidomethylation (C). Peptide identification in all 
205 fluids analyzed were validated using a 1\% FDR (false discovery rate) threshold calculated with 206 the Percolator algorithm [21].

207 Peptide and protein abundance quantification and statistical validation

208 Progenesis QI for Proteomics software (version 4.0, Waters) was used for the relative 209 quantification of the protein abundances by using co-detection to eliminate missing values. No

210 filters based on peptide by protein occurrences were applied for the protein quantification. The 211 relative quantitation of proteins according to the three groups (Control, S1 and S2 patients) was 212 performed using a between subject analysis and a Hi-3 method for which the three most abundant 213 peptides were used for protein quantification. Abundance variations of proteins with an ANOVA $214 p$-value under 0.05 were further considered. The protein fold change makes it possible to show a 215 difference of this protein abundance according to the groups when it is greater than 2 . The 216 potential biological role of each selected protein was verified and completed by a complete 217 bibliographic review to confirm its interest.

\section{Validation of protein abundance variations by ELISA}

\section{Selection of ELISA assays}

220 Human neuroserpin ELISA, BioVendor ${ }^{\circledR}$ (LOD-Limit of Detection: $0.03 \mathrm{ng} / \mathrm{mL}$ ), human NEO1

221 ELISA Kit, Mybiosource ${ }^{\circledR}$ (LOD: $5.00 \mathrm{pg} / \mathrm{mL}$ ) and human SCG2 ELISA Kit, Elabscience 222 Biotechnology ${ }^{\circledR}$ (LOD: $0.75 \mathrm{ng} / \mathrm{mL}$ ) were selected to detect levels of neuroserpin, neogenin and 223 secretogranin 2 in CSF, respectively. The level of neuroserpin detection on diagnosis samples 224 allowed further detection at 12 months follow-up. Human moesin ELISA kit, Abbexa Ltd® 225 (LOD: $0.054 \mathrm{ng} / \mathrm{mL}$ ) and human ITLN2 ELISA kit, Elabscience ${ }^{\circledR}$ (LOD: $3.75 \mathrm{ng} / \mathrm{mL}$ ) were used 226 to detect levels of moesin in urine and levels of ITNL2 in saliva, respectively. For each ELISA 
227 test, the protocol provided by the manufacturer was followed. Optical densities (OD) were 228 measured with a Multiskan go (Thermo Scientific $\left.{ }^{\circledR}\right)$ spectrophotometer.

\section{Statistical analysis}

230 Using the data obtained by ELISA, cut offs and receiver operating characteristic (ROC) curves 231 were made to determine the best sensitivity/specificity ratio for each marker. The significance has

232 been evaluated using Kruskal-Wallis test and Fisher's exact test for testing the null of 233 independence. The level of agreement with cut offs found in the literature was estimated using 234 Cohen's kappa coefficient and generalized linear models were used to make logistic regressions. 235 Tests were performed using R Core Team [22]. The following packages were used: ROCR for 236 drawing curves [23] and PMCMR for pairwise comparisons of Kruskal-Wallis test [24]. 


\section{Results}

\section{$240 \quad$ Population characteristics}

241 Demographic, clinical and biological data are summarized in Table 1. All screening cohort 242 selected patients and controls were male. Biological, neurological and parasitological 243 examination showed that no controls suffered from sleep or neurological disorders, no 244 trypanosomes were found in their blood or CSF, and their average WBC count was 4.61

$245 \mathrm{WBC} / \mu \mathrm{L}$ CSF. S1 patients had similar clinical characteristics to the control group but with 246 presence of trypanosomes in blood and an average of $1.33 \mathrm{WBC} / \mu \mathrm{L}$ CSF. S2 patients had 247 confirmed neurological signs and sleep disorders; their average WBC count was $195.79 \mathrm{WBC} / \mu \mathrm{L}$ 248 CSF.

249 The protein quantification cohort included 14 controls (sex ratio: 0.56), $23 \mathrm{~S} 1$ patients (sex ratio: 250 0.92) and 43 S2 patients (sex ratio: 0.54). Biological, neurological and parasitological 251 examination showed that no controls had trypanosomes in the blood or CSF. The CSF 252 examination of one of these controls revealed the presence of $8 \mathrm{WBC} / \mu \mathrm{L}$, but no co-infection was 253 detected for this patient, and the neurological examination did not reveal any disorders. Among 254 the controls only 2 patients had sleep disorders. All S1 patients had trypanosomes in the blood 255 and a WBC count between 0 and $4 \mathrm{WBC} / \mu \mathrm{L}$ CSF. None of the $\mathrm{S} 1$ patients had trypanosomes in 256 the CSF, and the neurological examination showed that 6 patients had neurological disorders, and 25710 had sleep disorders. All S2 patients had trypanosomes in the blood, and 23 out of 43 patients 258 had trypanosomes in the CSF. The WBC count of these patients ranged from 6 to $597 \mathrm{WBC} / \mu \mathrm{L}$ 259 CSF. Neurological examinations showed that 70\% (30/43) of these patients had neurological 260 disorders, and 67\% (29/43) had sleep disorders. 
261 For the quantification of proteins in urine and saliva, samples were not available for all controls 262 and patients. For urine samples, the analysis was done on 13 controls, 21 S1 patients and 38 S2 263 patients. For saliva samples, the analysis was done on 13 controls, 22 S1 patients and 38 S2 264 patients.

\section{Global LC-MS/MS analysis}

267 Searching the LC-MS/MS data for semi-tryptic peptides in the protein database allows the 268 identification of any possible protein degradation of the samples caused by the method and 269 duration of freezing. There were no major differences between the samples of occurrences of 270 peptides derived from non-tryptic endogenous proteases. This analysis was carried out on the 271 screening cohort samples and showed that the biological samples of these patients had not been 272 degraded.

273 The samples were tested for the presence of peptides described in the T. b. gambiense protein 274 database; however, although parasite proteins were identified in each of the 4 biological fluids 275 tested, they were not studied further owing to a lack of validation of protein identification.

276 However, they are present in the database published in supplementary files.

277 Analysis of the total number of different proteins identified in serum, CSF, saliva and urine for 278 each group of individuals (controls, S1 patients and S2 patients) (Figure 1) showed that S2 279 patients had a decrease in the number of different proteins expressed in the CSF compared with 280 control and S1 patients. For saliva, the mean total number of different proteins identified in S2 281 patients (472 different proteins) was less than the total number of different proteins identified in 282 S1 patients (594 different proteins) and by the control group (627 different proteins). The total 283 number of proteins expressed in sera was similar in the different groups. For urine, the lowest 284 total number of proteins identified was found in the controls. 
285 Figure 1: Distribution of the number of proteins identified in the serum, CSF, saliva and urine of

286 the screening cohort with respect to disease stage.

287 Captions: The total number of different proteins identified by LC-MS/MS analysis in serum, 288 cerebrospinal fluid (CSF), urine and saliva in boxplots and a table. Boxplots show the maximum 289 and minimum number of proteins identified by LC-MS/MS, the means and quartiles for each 290 fluid analyzed. For serum, CSF and urine data there are 3 controls (C), 3 patients with stage 1 291 (S1) disease and 4 patients with Stage 2 (S2) disease. For saliva there are 2 controls, 3 patients 292 with S1 disease and 4 patients with S2 disease. The mean number of different proteins identified 293 by LC-MS/MS analysis in serum, cerebrospinal fluid (CSF), urine and saliva are available in 294 supplementary data. 


\section{LC-MS/MS analysis and protein quantification in sera}

296 The proteomic analysis of the 10 screening cohort serum samples showed the presence of 269 297 proteins. The 10 best-scored proteins are presented in table 2 . These data are heavily skewed 298 owing to the very high levels of some serum proteins, such as albumin and immunoglobulins, 299 despite the use of depletion protocols. This is highlighted by the presence of proteins with high 300 identification scores, which are normally depleted, in table 2. As such, any changes in protein 301 levels specific to HAT are not statistically pertinent.

\section{LC-MS/MS analysis and protein quantification in CSF}

304 The proteomic analysis of the screening cohort CSF samples showed the presence of 491 305 proteins. The relative abundances of these proteins were estimated by label-free quantification 306 with Progenesis QI software. Among these proteins, 159 were found differentially abundant 307 (ANOVA $p$-value lower than 0.05 and Fold Change higher than 2) between controls, S1 or S2 308 patients. After analysis of these 159 proteins on the basis of their statistical data (ANOVA $p$ 309 value and fold change), their differences attributable to disease stage, and their biological role, 37

310 proteins presented potential interest in HAT characterization (Table 3). Neogenin, secretogranin 2 311 and neuroserpin were chosen for protein quantification in CSF samples as their results showed 312 the best combination of our defined criteria. Briefly, the ANOVA $p$-value calculated for neogenin 313 is $3.82 \times 10^{-5}$, and the fold change is close to infinity; the average normalized abundance (ANA) 314 calculations showed an expression of this protein only in controls and S1 patients $\left(2.72 \times 10^{4}\right.$ and $3152.17 \times 10^{4}$, respectively) (Table 3 ). The ANOVA $p$-value calculated for secretogranin 2 is $5.45 \times 10^{-}$ $316{ }^{5}$ and the fold change is 11.27 (Table 3). More secretogranin 2 is found in the CSF of healthy

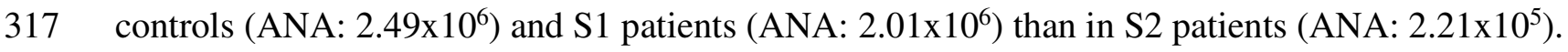


318 The most significant ANOVA result was obtained for neuroserpin at $2.61 \times 10^{-8}$, and the Fold

319 Change was close to infinity (Table 3). This protein is present in the CSF of healthy controls 320 (ANA: $2.5 \times 10^{4}$ ) and S1 patients (ANA: $2.32 \times 10^{4}$ ) but not in S2 patients.

321 Protein quantification by ELISA was performed for the 3 proteins meaningful results were not obtained for neogenin and secretogranin 2 . For neogenin, the amount was too low to be detect by ELISA, and for secretogranin 2, similar concentrations were found for controls, $S 1$ and S2 patients. Mean values obtained were $0.27 \mathrm{ng} / \mathrm{mL}$, with a standard deviation of 0.003 . It was thus not possible to use secretogranin 2 as a possible marker of differentiation for patients or controls. Protein quantification by ELISA was performed for the 3 proteins, but for neogenin an secretogranin 2, the amount was too low to be detected by ELISA. It was therefore not possible to use them as a possible marker of differentiation for patients or controls. Only the neuroserpin ELISA results showed significant differences (Figure 2) and allowed statistical tests to be 330 performed for further analysis. There was no difference in neuroserpin CSF concentration 331 between the control and patients at inclusion when analyzed by the Kruskal-Wallis test; however, 332 neuroserpin levels were significantly different $(p<0.05)$ between S1 and S2 patients. ROC curve 333 analysis was used to determine the threshold level of neuroserpin for discriminating S2 patients 334 from S1 patients (area under the curve (AUC): 0.72). It was determined that a level of CSF 335 neuroserpin below $4.99 \mathrm{ng} / \mathrm{mL}$ was indicative of a patient having S2 disease (sensitivity: 0.94 and 336 specificity: 0.58). Logistic regression analysis showed that age and sex of individuals have no 337 effect on CSF neuroserpin concentration; however, there was a correlation between neuroserpin 338 concentration and presence of sleep disorders (odds ratio: $2.1 \times 10^{-02}\left(\mathrm{CI}: 1.0 \times 10^{-3} ; 1.47 \times 10^{-1}\right), p<$ 3390.01 ) and neurological disorders (odds ratio: $6.3 \times 10^{-2}$ (CI: $\left.0.9 \times 10^{-2} ; 2.32 \times 10^{-1}\right), p<0.001$ ). 340 Similarly, a link could be made between the presence of trypanosomes in the CSF and the 341 concentration of neuroserpin (odds ratio: $5.09 \times 10^{-4}$ (CI: $1.93 \times 10^{-4} ; 4.22 \times 10^{-2}$ ), $p<0.001$ ). 
342 Figure 2: Changes in the neuroserpin concentration in CSF of controls and patients with stage 1

343 and stage 2 HAT at inclusion and after 12 months

344 Captions: Neuroserpin concentrations in the CSF for 14 healthy controls, 23 S1 patients and 43

345 S2 patients; the concentrations for $5 / 14$ of the controls $16 / 23$ of the $S 1$ patients and 28/43 of the

346 S2 patients after 12 months of treatment are also shown.

347 
348 Neuroserpin levels were then tested for association with sleep and neurological disorders and the 349 presence of trypanosomes in the CSF. The Kruskal-Wallis test revealed that CSF neuroserpin 350 could act as a marker for these disease-associated pathologies $(p<0.05)$. A ROC curve was used 351 to determine the threshold of $5.09 \mathrm{ng} / \mathrm{mL}$, below which patients had sleep disorders (AUC: 0.79; 352 sensitivity: 0.72 and specificity: 0.67$)$. The ROC curve analysis also allowed us to determine a 353 threshold of $4.97 \mathrm{ng} / \mathrm{mL}$ of CSF neuroserpin (AUC: 0.77 ), below which the patients had 354 neurological disorders (sensitivity: 0.9 and specificity: 0.59). The threshold of CSF neuroserpin 355 determined by ROC curve analysis for discriminating the presence of trypanosomes in the CSF 356 (AUC $=0.95)$ is $4.83 \mathrm{ng} / \mathrm{mL}$, below which is indicative of CSF invasion by trypanosomes 357 (sensitivity: 0.98 and specificity: 0.91). The discriminating power of CSF neuroserpin was tested 358 against the parasitological examination of CSF (gold standard) with an agreement of 0.88 359 (Cohen's kappa coefficient), which is an excellent concordance.

360 At follow-up, at 12 months following treatment, the neuroserpin concentration was quantified in 361 the CSF in 5/14 of the controls, $16 / 23$ of the S1 patients and 28/43 of the S2 patients. Kruskal362 Wallis analysis showed that there was no difference in neuroserpin levels between the 3 groups 363 after 12 months post-treatment, and the concentrations at 12 months were close to those found in 364 the control and S1 patients at inclusion. The mean neuroserpin concentration in the CSF in all the 365 groups is $5.13 \mathrm{ng} / \mathrm{mL}$ (Figure 2).

\section{LC-MS/MS analysis and protein quantification in urine}

368 The proteome analysis of urine samples showed the presence of 664 proteins, and 32 proteins 369 were differentially abundant (ANOVA $p$-value lower than 0.05 and Fold Change higher than 2) 370 between the control and the $\mathrm{S} 1$ or the $\mathrm{S} 2$ patients. From these 32 proteins, 8 were chosen as

371 interesting (Table 4). Moesin appeared to be the most promising protein for quantification by 
372 ELISA at inclusion. The ANOVA $p$-value for moesin analysis was $9.38 \times 10^{-3}$ and its fold change was 47.11 (Table 4). Moesin is increased in S1 patients (ANA: 7.12x104) and S2 patients (ANA: $1.57 \times 10^{4}$ ) compared with the controls (ANA: 1511.77). Quantification of moesin at 12 months

375 follow-up was not possible owing to the low number of urine samples available.

The moesin ELISA was performed on samples from 59 patients from both S1 and S2 patients and 13 uninfected controls. The Kruskal-Wallis test revealed a significant difference in moesin levels $(p<0.05)$ between controls and patients with HAT. The threshold for discriminating controls from patients was determined with ROC curve analysis $(\mathrm{AUC}=0.70)$. A level of moesin above $0.448 \mathrm{ng} / \mathrm{mL}$ (sensitivity: 0.64 and specificity: 0.61) in urine is indicative of HAT disease.

381 Further characterization of moesin levels between $\mathrm{S} 1(\mathrm{n}=21)$ and $\mathrm{S} 2$ patients $(\mathrm{n}=38)$ compared 382 with uninfected controls $(\mathrm{n}=13)$ was performed. No statistical difference in moesin abundance 383 levels was observed between uninfected controls and S1 patients and no significant difference 384 was observed between S1 and S2 patients. However, when comparing the uninfected controls and 385 S2 patients, a significant difference in moesin levels was found $(p<0.05)$. ROC curve analysis 386 (AUC: 0.72) was used to determine a urine moesin threshold of $0.60 \mathrm{ng} / \mathrm{mL}$ (sensitivity: 0.63 and 387 specificity: 0.65) above which patients had S2 HAT. Using logistic regression, it was shown that 388 the moesin concentrations were not influenced by sex, age, presence of trypanosomes in CSF, or 389 sleep and neurological disorders.

\section{$391 \quad$ LC-MS/MS analysis and protein quantification in saliva}

392 The screening was carried out on the screening cohort but with only 2 controls (owing to an error 393 in tube labelling). The proteome screening of saliva allows the identification of 954 proteins. 394 Among these 954 proteins, 137 were found to be differentially abundant (ANOVA $p$-value lower 395 than 0.05 and fold change higher than 2) between the control and the S1 or the S2 patients, and 
39624 were chosen for their particular interest (Table 5). Among them intelectin 2 (ITLN2) was 397 chosen for quantification by ELISA. ITLN2 had an ANOVA of $1.23 \times 10^{-4}$ and a Fold Change of 398120.23 as determined by quantitative proteomics; ANA, determined by Progenesis QI software 399 analysis, showed lower ITLN2 concentration in the saliva of patients in both stages (S1 ANA: 400258.69 ; S2 ANA: 350.60) than controls (ANA: 3.11x104).

401 Saliva ITLN2 concentrations measured by ELISA of controls $(n=13)$ and those of patients $(n=$ 402 60) were compared with the Kruskal-Wallis test. There was no significant difference between the 403 two populations $(p=0.40)$. Saliva ITLN2 concentrations were then compared between S1 404 patients $(n=22)$, the S2 patients $(n=38)$ and uninfected controls $(n=13)$ using the Kruskal405 Wallis test. There was no significant difference in ITLN2 levels between controls, S1 and S2 406 patients $(p=0.06)$. Therefore, it was not possible to determine a threshold for this protein (AUC $407=0.59)$. 
409 This is, to our knowledge, the first simultaneous proteomic characterization of 4 biological fluids

410 (serum, CSF, saliva and urine) from the same HAT patients. The proteome screening analysis by

411 LC-MS/MS has revealed 69 proteins (37 proteins in CSF, 8 proteins in saliva and 24 proteins in

412 urine) that could be interesting for diagnosis or staging of the disease. The potential of 5 proteins

413 (3 proteins in CSF, 1 protein in urine and 1 protein in saliva) were further verified as biomarkers

414 in diagnosis or staging. These assays are a preliminary step in the identification of the entire 415 proteome of HAT patients.

416 The semi-tryptic peptide analysis of the database showed that the method and the freezing 417 duration of our samples did not alter the proteome quality. However, very few proteins or 418 degraded fragments from the parasite were identified owing to poor Mascot scores. This may be 419 due to the low quantity of parasitic proteins relative to the amount of human proteins and/or to 420 limitations or absence of $T$. $b$. gambiense proteins in the existing database. This needs to be 421 further investigated, which is why our study was focused on the human proteome and the 422 detection of biomarkers for S2 patients and not on parasite proteins.

423 In sera, the label-free quantification did not identify any protein of notable interest (ANOVA: < 4240.05 and Fold Change: > 2). The quantification by LC-MS/MS of an exhaustive set of proteins in 425 serum is difficult; this is partly due to the complexity of the serum, which contains a large 426 number of different proteins with an extremely large range of expression [25], [26]. In this case, 427 despite the depletion step carried out, the presence of a large quantity of proteins (mainly 428 albumins and globulins) impedes quantification of other proteins as shown in other studies [27].

429 In the CSF, the protein composition showed a clear decrease in the diversity and number of 430 identified proteins in patients with S2 disease. This result is surprising but can be explained by 
431 two physiopathological mechanisms that may act together. The first is trypanosome-induced 432 immunosuppression [28]-[30], which is a marked weakening of the humoral response owing to 433 massive B cell death [31], [32]. Furthermore, it has been described that the release of 434 trypanosome suppression immunomodulating factor by the parasite triggers the development of 435 suppressive M1 macrophages [33] and blocks T cell proliferation [34]. This immunosuppression 436 could explain the decrease in the number of proteins found in the CSF of the patients with S2 437 disease because the disappearance of the immune cells implies a decrease of the proteins related 438 to them. The second explanation is a leakage or resorption of nervous system proteins owing to 439 the permeabilization of the blood-brain barrier [35], [36]. The loss of nervous system proteins 440 and increase in plasma-associated protein, such as complement system proteins, albumin, 441 transthyretin and apolipoproteins has been described by others in CNS infections altering the 442 blood-brain barrier [37]-[39] and was corroborated in the CSF analysis of our study.

444 In CSF, the analysis allowed the identification of 491 proteins, of which many had been 445 previously associated with HAT, such as vascular cell adhesion protein 1 (VCAM1) [40], [41] 446 and osteopontin (SPP1) [42]. The study focused on 37 proteins that were differentially expressed 447 between the uninfected controls, S1 and S2 patients, and 3 proteins - namely neogenin, 448 secretogranin 2 and neuroserpin - were chosen for further analysis by ELISA [43]-[50]. 449 Neogenin is a protein associated with the nervous system, and it has already been proposed as a 450 biomarker in other pathologies [45], [50]. In the brain, neogenin is a receptor for many proteins, 451 including repulsive guidance molecule (RGM) family members, which is involved in axon 452 guidance, apoptosis and neuronal differentiation [46], [50]. The use of the RGMa-neogenin 453 signaling pathway as a therapeutic target to overcome inflammatory and neurodegenerative 454 diseases has already been proposed [50]. Secretogranin 2 is a soluble member of the granin 
455 protein family, which are widely distributed in neuroendocrine and nervous system tissues. Granins are stored in large dense core vesieles within neurens; secretogranin 2 can also be detected in glial cells [43]. Secretogranin 2 has numerous functions, including neurite outgrowth and chemoattractive effects on monocytes, eosinophils and endothelial cells [43]. In 2013, Jakobsson et al proposed secretogranin 2 as a CSF marker for severe forms of bipolar disorder. Patients with bipolar disorder have defects in the regulatory secretory pathway; one of the altered proteins is secretogranin 2 [48], and reduction is linked to severe forms. Reduced levels of secretogranin 2 and secretogranin 3 were observed in serum and CSF samples of patients with multiple sclerosis [45], [47], [49]. In our HAT sample collection, neogenin and secretogranin 2 were highlighted by LC MS/MS analysis; however, the ELISA assay used seemed unable to detect these proteins, which may be due to the detection limit of the commercial ELISA test being too high for the samples in this study. In our HAT sample collection, neogenin and secretogranin 2 were highlighted by LC-MS/MS analysis; however, our patients had neogenin and secretogranin 2 concentrations under the ELISA assay limit of detection.

469 Finally, among the tested proteins, only neuroserpin allowed the discrimination of disease stage with a decrease in neuroserpin concentrations with disease progression. This is the first study

471 showing a link between neuroserpin and HAT. Neuroserpin is a protein belonging to the serine 472 protease inhibitor superfamily, which is expressed throughout the nervous system but more 473 particularly at the latter stages of the development of neuronal cells [44], [51], [52]. Neuroserpin 474 inhibits the activation of tissue plasminogen and has an essential role in axogenesis, synaptic 475 plasticity [53], memory and brain development [54], [55]. Neuroserpin is linked to familial 476 encephalopathy with neuroserpin inclusion bodies (FENIB) [56]. This dementia is due to point 477 mutations favoring the polymerization of neuroserpin and its retention in endoplasmic reticulum 478 of neurons [56]-[58]. This protein is also associated with Alzheimer disease, but its role is not yet 
479 clearly identified [59]-[61]. To date, we have no knowledge of work studying the relationship

480 between neuroserpin and HAT. The decrease in late stage disease could be due to the fact that 481 neuroserpin is predominantly expressed in the neurons of the hippocampus, caudate and cerebral 482 cortex [62], [63]. The hippocampus and the caudate are close to the choroid plexus, which is 483 described in the literature as the first route of entry of the parasite into the brain owing to the 484 absence of the blood-brain barrier at this location [64]-[66]. It is probable that these regions are 485 the first to be affected by the presence of the trypanosome. ELISA quantification allowed us to 486 determine a cut-off point for neuroserpin, below which HAT patients may be considered to be in 487 S2 (4.99 ng/mL; sensitivity: 0.94 and specificity: 0.58) at diagnosis. Patients with a neuroserpin 488 concentration greater than $4.99 \mathrm{ng} / \mathrm{mL}$ are considered in $\mathrm{S} 1$ of the disease. Levels had returned to 489 normal at 12 months follow up, suggesting that the decrease is directly linked to the presence of 490 the parasite or the elicited immune reaction. It was also possible to determine that the onset of 491 sleep disorders was associated with a CSF neuroserpin concentration of less than $5.09 \mathrm{ng} / \mathrm{mL}$. 492 This last cut-off could explain how some patients with S1 disease present symptoms of sleep 493 disorders [67], [68]. Similarly, the presence of trypanosome in the CSF was correlated with a 494 CSF neuroserpin concentration of less than $4.84 \mathrm{ng} / \mathrm{mL}$. Each of these cut-offs correlate with 495 classical stage markers, indicating that neuroserpin may be considered as a good additional or 496 unique marker if its concentration is easy to quantify.

498 The identification of biomarkers in alternative fluids such as urine and saliva is extremely 499 interesting for field screenings or use in resource-limited countries. Access to these fluids is 500 noninvasive, and collection can be done by non-qualified people, or they can even can be used 501 for self-diagnosis [69], [70]. Currently, saliva is a source of biomarkers for neurological diseases 502 [71], HIV [72], diabetes [73]-[75] and cancer [76], [77]; urine is used for the diagnosis of 
503 osteoclastogenesis [78], urological cancer [79], and proteins in the urine have been identified as

504 potential biomarkers for breast cancer [80], Alzheimer disease [81] and Parkinson disease [82].

505 In urine, proteins linked to infectious processes have been highlighted. Moesin was the most 506 interesting according to our identification criteria. This protein belongs to the family of ezrin507 radixin-moesin (ERM) proteins, and it is involved in angiogenesis. In fact, the phosphorylation 508 of moesin allows the mediation of endothelial angiogenesis [83]. This protein also participates in 509 the connection between the cytoskeleton and the plasma membrane of human cells. This property 510 allows this protein to limit infection with herpes simplex virus 1 [84]. It has been shown to have a 511 role in invasion of Trypanosoma cruzi amastigotes into human cells [85]. Moesin is also involved 512 in the regulation, proliferation and adhesion of human lymphoid cells [86]. A mutation of this 513 protein leads to primary immunodeficiency [87]. The involvement of moesin in kidney lesions 514 was established by Chen et al [88]; however, its role is not clear. The ERM complex intervenes in 515 the cellular dynamics by taking part in the mobility of cancer cells described in oral cancers and 516 carcinomas [89], [90]. In our study, moesin levels were elevated in urine samples from S1 and S2 517 patients compared with uninfected controls. This result was corroborated by the ELISA 518 quantification. ELISA quantification shows that there is a significant difference between moesin 519 concentrations in uninfected controls compared with patients. Furthermore, a difference in 520 moesin concentration was observed between the uninfected controls and S2 patients, which could 521 make it possible to discriminate stage when the presence of the parasite is established in the 522 blood. It was subsequently impossible to carry out the analysis at 12-months follow-up as not 523 enough samples were available.

525 In saliva, 24 potential interesting proteins were identified that are differentially expressed, and 526 ITLN2 was chosen as a potential candidate biomarker owing to its physiopathological 
background. However, ITLN2 levels detected by ELISA could not discriminate controls from

528 patients, nor S1 from S2 patients $(p=0.06)$. It does not appear aberrant to find this protein in an

529 inflammatory pathology such as HAT [91], [92]. The intelectin families, and particularly ITLN2,

530 are proteins expressed principally in the small intestine. ITLN2 is involved in host-pathogen

531 interactions [93] and iron metabolism [94] and allergic inflammation [91]. Studies are currently

532 determining any potential antimicrobial and anti-parasitic activity of ITLN2 [91], [92], [95].

533 However, the presence of ITLN2 and its role in saliva remains unexplained. The quantification of 534 this protein on a larger sample could make it possible to identify the pathophysiological role of 535 this protein in HAT.

537 There can be some bias in saliva and urine analysis. In case of saliva, intra- and inter-individual 538 composition variations can be influenced by many parameters, such as salivary flow, sex, age, the 539 subject's emotional state, season, nycthemeral rhythm and medication [96]. In the same way, 540 external elements to the salivary system, such as nasal and bronchial secretions, the gingival 541 fluid, epithelial cells, microbial flora and food debris, can modify its composition [97], [98]. It is 542 recommended to perform the saliva collection before brushing the teeth and at least 30 minutes 543 after any ingestion of food [99]. For urine, the time of sample collection was not calibrated 544 (between 7 am and $1 \mathrm{pm}$ ) and thus may lead to variations in urine composition and concentration. 545 In this study, these variations could not all be controlled and may constitute a bias.

546 One weakness of this study is the number of patients that were selected for the screening by LC547 MS/MS analysis. Indeed, for practical reasons 10 patients were selected among the 247 included 548 in the cohort for the analysis of screening, for which there is homogeneous data (age, sex and no 549 co-infection detected). Despite the low number of patient samples analyzed by LC-MS/MS, the 550 patient sampling in each group (controls, S1 and S2) is statistically homogenous. Another 
551 possible criticism is the lack of uniformity in the sampling times, which is especially important in

552 the case of urine and saliva.

\section{Conclusion}

554 In conclusion, our work allowed the characterization of a large number of proteins presenting an 555 interest in the understanding of HAT pathophysiology and diagnosis. The high sensitivity of new 556 technologies such as LC-MS/MS allow the discovery of new candidate disease marker and open 557 the path to other more accessible biological fluids like urine or saliva. Our work identified two 558 potential new markers, neuroserpin and moesin, the latter of which is found in urine, which could 559 simplify diagnostic strategies in the field. 
Human-samples of sera, CSF, saliva and wrine from-sereening cohort were prepared for LC MS/MS analysis. Human African trypanosomiasis samples (sera, CSF, saliva and urine) from a screening cohort were prepared for characterization of disease biomarkers by LC-MS/MS analysis. Bottom-up identification of proteins allows to categorize 269 proteins in the serum, 491 proteins in the CSF, 954 proteins in the saliva and 664 proteins in the urine. Among these proteins identified, 37 proteins in the CSF, 24 proteins in the saliva and 8 proteins in the urine were differentially abundant between the control, the S1 or the S2 patients and were of interest for HAT diagnosis. Among these proteins, 5 were assayed by ELISA in the protein quantification cohort: neogenin, secretogranin 2 and neuroserpin in the CSF; intelectin 2 in the saliva and moesin in the urine.

*For saliva screening cohort: controls $(n=2), S 1$ patients $(n=3)$ and S2 patients $(n=4)$.

\section{Supplementary data}

Table represents the average number of different proteins identified by LC-MS/MS analysis in serum, cerebrospinal fluid (CSF), urine and saliva. For serum, CSF and urine data there are 3 controls (C), 3 patients with stage 1 (S1) disease and 4 patients with Stage 2 (S2) disease. For saliva there are 2 controls, 3 patients with $\mathrm{S} 1$ disease and 4 patients with S2 disease.

\section{Highlights}

LC-MS/MS analysis allow the discovery of new candidate disease markers for HAT.

Neuroserpin and moesin are two potential new markers that could simplify diagnostics. CSF protein composition showed a eleardecrease of identified proteins in S2 patients. Easily accessible biological fluids, like urine, could be used for HAT diagnosis.

\section{Ethics approval and consent to participate}

Ethical clearance was obtained from the Direccao National de Saude Publica, Ministerio da Saude, Angola. The authorization for automated processing of personal data relating to the study was obtained from the Comite Consultatif sur le Traitement de l'Information en matière de Recherche dans le domaine de la Santé (CCTIRS) ( $\left.\mathrm{N}^{\circ} 08.228 \mathrm{bis}\right)$

\section{Consent for publication}

593 Written informed consent was obtained from all participants and, for participants below 18 years 594 of age, from their parents or guardians, prior to enrolment. Any individual who declined to 595 participate was managed according to the standard procedures of the national HAT control 596 program. 
599 The complete data sets are available in the PRIDE partner repository [100] under the 600 identification number : PXD007842 as .raw files, Proteome Discoverer 2.1 .pdResult file, 601 associated pep.xml and xlsx files, and label-free report generated by Progenesis QI.

602 Username: reviewer10851@ebi.ac.uk

603 Password: NL6d28RK

604 Supporting Information Legends: Identification and relative quantification of all peptides/proteins 605 from the proteomics experiments and according to the different experimental conditions are 606 publicly available via ProteomeXchange and the PRIDE partner repository under the 607 identification number: PXD007842 as.raw files, Proteome Discoverer 2.1. pdResult file, 608 associated pep.xml and xlsx files, and label-free report generated by Progenesis QI.

609

610 Competing interests

611 The authors declare that they have no competing interests

612

613 Funding

614 This work was supported by the Foundation for Innovative and New Diagnostic (FIND 2008) 615 (https://www.finddx.org) and Conseil Regional de la Nouvelle Aquitaine and INSERM.

617 Acknowledgements

618 The manuscript has been revised for the English by an independent scientific language editing 619 service. 


\section{References}

621 [1] P. Büscher, G. Cecchi, V. Jamonneau, and G. Priotto. Human African trypanosomiasis. The Lancet. 2017; 390:2397-2409.

[2] Strategic and Technical Advisory Group on NTDs (STAG).10th meeting of the Strategic and Technical Advisory Group for Neglected Tropical Diseases. WHO, Geneva, Switzerland. 2017.

[3] WHO. Report of the second WHO stakeholders meeting on gambiense human African trypanosomiasis elimination. 2016.

[4] P. P. Simarro, A. Diarra, J. A. Ruiz Postigo, J. R. Franco, and J. G. Jannin. The Human African Trypanosomiasis Control and Surveillance Programme of the World Health Organization 2000-2009: The Way Forward. PLoS Negl. Trop. Dis. 2011 ; 5 (2): e1007.

[5] J. R. Franco, P. P. Simarro, A. Diarra, and J. G. Jannin. Epidemiology of human African trypanosomiasis. Clin. Epidemiol. 2014; 6: 257-275.

[6] R. Brun, J. Blum, F. Chappuis, and C. Burri. Human African trypanosomiasis. The Lancet. 2010; 375 (9709): 148-159.

[7] S. Mogk, A. Meiwes, S. Shtopel, U. Schraermeyer, M. Lazarus, B. Kubata et al. Cyclical Appearance of African Trypanosomes in the Cerebrospinal Fluid: New Insights in How Trypanosomes Enter the CNS. PLoS ONE. 2014; 9 (3): e91372.

[8] S. Bisser, C. Lumbala, E. Nguertoum, V. Kande, L. Flaveau, G. Vatunga et al. Sensitivity and Specificity of a Prototype Rapid Diagnostic Test for the Detection of Trypanosoma brucei gambiense Infection: A Multi-centric Prospective Study. PLoS Negl. Trop. Dis. 2016; 10 (4): e0004608.

[9] P. Lutumba, J. Robays, C. Miaka, V. Kande, D. Mumba, P. Büsher et al. Validity, cost and feasibility of the mAECT and CTC confirmation tests after diagnosis of African of sleeping sickness. Trop. Med. Int. Health TM IH. 2006; 11 (4): 470-478.

[10] P. Büscher, D. Mumba Ngoyi, J. Kaboré, V. Lejon, J. Robays, V. Jamonneau et al. Improved Models of Mini Anion Exchange Centrifugation Technique (mAECT) and Modified Single Centrifugation (MSC) for Sleeping Sickness Diagnosis and Staging. PLoS Negl. Trop. Dis. 2009; 3 (11): e471.

[11] D. Mumba Ngoyi, J. Menten, P. P. Pyana, P. Büscher, and V. Lejon. Stage determination in sleeping sickness: comparison of two cell counting and two parasite detection techniques. Trop. Med. Int. Health TM IH. 2013; 18 (6): 778-782.

[12] A. H. Fairlamb. Chemotherapy of human African trypanosomiasis: current and future prospects. Trends Parasitol. 2003; 19 (11): 488-494.

[13] V. K. B. K. Mesu, W.M. Kalonji, C. Bardonneau, O. V. Mordt, S. Blesson, F. Simon et al. Oral fexinidazole for late-stage African Trypanosoma brucei gambiense trypanosomiasis: a pivotal multicentre, randomised, non-inferiority trial. The Lancet. 2018; 391 (10116): 144154.

[14] Z. Meng and T. D. Veenstra. Proteomic analysis of serum, plasma, and lymph for the identification of biomarkers. Proteomics Clin. Appl. 2007; 1 (8): 747-757.

[15] J. Rouillon, A. Zocevic, T. Leger, C. Garcia, J.M. Camadro, B. Ubb et al. Proteomics profiling of urine reveals specific titin fragments as biomarkers of Duchenne muscular dystrophy. Neuromuscul. Disord. NMD. 2014; 24 (7): 563-573. 
[16] J. Beretov, V. C. Wasinger, E. K. A. Millar, P. Schwartz, P. H. Graham, and Y. Li. Proteomic Analysis of Urine to Identify Breast Cancer Biomarker Candidates Using a Label-Free LC-MS/MS Approach. PloS One. 2015; 10 (11): e0141876.

[17] C.-C. Wu, H.-W. Chu, C.-W. Hsu, K.-P. Chang, and H.-P. Liu. Saliva proteome profiling reveals potential salivary biomarkers for detection of oral cavity squamous cell carcinoma. Proteomics. 2015; 15 (19): 3394-3404.

[18] M. A. Collins, J. An, B. L. Hood, T. P. Conrads, and R. P. Bowser. Label-Free LC-MS/MS Proteomic Analysis of Cerebrospinal Fluid Identifies Protein/Pathway Alterations and Candidate Biomarkers for Amyotrophic Lateral Sclerosis. J. Proteome Res. 2015; 14 (11): 4486-4501.

[19] M. Hamilton. A rate scale for depression. J. Neurol. Neurosurg. Psychiatry. 1960; 23: 5662.

[20] D. V. Sheehan, Y. Lecrubier, K. H. Sheehan, P. Amorim, J. Janavs, E. Weillers et al. The Mini-International Neuropsychiatric Interview (M.I.N.I.): the development and validation of a structured diagnostic psychiatric interview for DSM-IV and ICD-10. J. Clin. Psychiatry. 1998;59 Suppl 20:22-33-57.

[21] M. Brosch, L. Yu, T. Hubbard, and J. Choudhary. Accurate and sensitive peptide identification with Mascot Percolator. J. Proteome Res. 2009; 8 (6): 3176-3181.

[22] R Core Team. R: A Language and Environment for Statistical Computing. Vienna, Austria: R Foundation for Statistical Computing, 2016.

[23] T. Sing, O. Sander, N. Beerenwinkel, and T. Lengauer. ROCR: Visualizing the Performance of Scoring Classifiers. 2015.

[24] T. Pohlert. PMCMR: Calculate Pairwise Multiple Comparisons of Mean Rank Sums. 2016.

[25] L. Anderson. Candidate-based proteomics in the search for biomarkers of cardiovascular disease. J. Physiol. 2005; 563 (1): 23-60.

[26] S. Hu, J. A. Loo, and D. T. Wong. Human body fluid proteome analysis. Proteomics. 2006; 6 (23): 6326-6353.

[27] N. L. Anderson and N. G. Anderson. The Human Plasma Proteome History, Character, and Diagnostic Prospects. Mol. Cell. Proteomics. 2002; 1 (11): 845-867.

[28] G. Low and A. Castellani. Report of the Sleeping Sickness Commission. Proc R Soc London. London; 1903.

[29] K. A. Taylor. Immune responses of cattle to African trypanosomes: protective or pathogenic? Int. J. Parasitol. 1998; 28 (2): 219-240.

[30] T. N. Baral. Immunobiology of African trypanosomes: need of alternative interventions. J. Biomed. Biotechnol. 2010; 2010: 389153.

[31] M. Radwanska, P. Guirnalda, C. D. Trez, B. Ryffel, S. Black, and S. Magez. Trypanosomiasis-Induced B Cell Apoptosis Results in Loss of Protective Anti-Parasite Antibody Responses and Abolishment of Vaccine-Induced Memory Responses. PLOS Pathog. 2008; 4 (5): e1000078.

[32] V. Bockstal, P. Guirnalda, G. Caljon, R. Goenka, J. C. Telfer, D. frenkel et al. T. brucei Infection Reduces B Lymphopoiesis in Bone Marrow and Truncates Compensatory Splenic Lymphopoiesis through Transitional B-Cell Apoptosis. PLOS Pathog. 2011; 7 (6): e1002089.

[33] J. Gómez-Rodríguez, B. Stijlemans, G. De Muylder, H. Korf, L. Brys, M. Berberof et al. Identification of a parasitic immunomodulatory protein triggering the development of suppressive M1 macrophages during African trypanosomiasis. J. Infect. Dis. 2009; 200 (12): 1849-1860. 
[34] B. Stijlemans, G. Caljon, J. Van Den Abbeele, J. A. Van Ginderachter, S. Magez, and C. De Trez. Immune Evasion Strategies of Trypanosoma brucei within the Mammalian Host: Progression to Pathogenicity. Front. Immunol. 2016; 7: 233.

[35] D. J. Grab, O. Nikolskaia, Y. V. Kim, J. D. Lonsdale-Ecces, S. Ito, T. Hara et al. African trypanosome interactions with an in vitro model of the human blood-brain barrier. J. Parasitol. 2004; 90 (5): 970-979.

[36] D. J. Grab, J. C. Garcia-Garcia, O. Nikolskaia, Y. V. Kim, A. Brown, C. A. Pardo et al. Protease Activated Receptor Signaling Is Required for African Trypanosome Traversal of Human Brain Microvascular Endothelial Cells. PLoS Negl. Trop. Dis. 2009; 3 (7): e479.

[37] R. Jurado and H. K. Walker. Cerebrospinal Fluid. In: Clinical Methods: The History, Physical, and Laboratory Examinations, 3rd ed., H. K. Walker, W. D. Hall, and J. W. Hurst, Eds. Boston: Butterworths; 1990.

[38] H. Reiber and J. B. Peter. Cerebrospinal fluid analysis: disease-related data patterns and evaluation programs. J. Neurol. Sci. 2001; 184 (2): 101-122.

[39] B. J. Blyth, A. farhavar, C. Gee, B. Hawthorn, H. He, A. Nayak et al. Validation of Serum Markers for Blood-Brain Barrier Disruption in Traumatic Brain Injury. J. Neurotrauma. 2009; 26 (9): 1497-1507.

[40] C. Mulenga, J. D. Mhlanga, K. Kristensson, and B. Robertson. Trypanosoma brucei brucei crosses the blood-brain barrier while tight junction proteins are preserved in a rat chronic disease model. Neuropathol. Appl. Neurobiol. 2001; 27 (1): 77-85.

[41] A. Hainard, N. Tiberti, X. Robin, D. M. Ngoyi, E. Matovu, J. C. Enyaru et al. Matrix metalloproteinase- 9 and intercellular adhesion molecule 1 are powerful staging markers for human African trypanosomiasis. Trop. Med. Int. Health. 2011; 16 (1): 119-126.

[42] N. Tiberti, A Hainard, V. Lejon, X. Robin, D. M. Ngoyi, N. Truck et al. Discovery and verification of osteopontin and Beta-2-microglobulin as promising markers for staging human African trypanosomiasis. Mol. Cell. Proteomics MCP. 2010; 9 (12): 2783-2795.

[43] R. Fischer-Colbrie, R. Kirchmair, A. Schobert, C. Olenik, D. K. Meyer, and H. Winkler. Secretogranin II Is Synthesized and Secreted in Astrocyte Cultures. J. Neurochem. 1993; 60 (6): 2312-2314.

[44] G. A. Hastings, T. A. Coleman, C. C. Haudenschild, S. Stefansson, E. P. Smith, R. Barthlow et al. Neuroserpin, a brain-associated inhibitor of tissue plasminogen activator is localized primarily in neurons. Implications for the regulation of motor learning and neuronal survival. J. Biol. Chem. 1997; 272 (52): 33062-33067.

[45] N. Mattsson, U. Rüetschi, V. N. Podust, M. Stridsberg, S. Li, O. Andersen. Cerebrospinal fluid concentrations of peptides derived from chromogranin B and secretogranin II are decreased in multiple sclerosis. J. Neurochem. 2007; 103 (5): 1932-1939.

[46] N. H. Wilson and B. Key. Neogenin: one receptor, many functions. Int. J. Biochem. Cell Biol. 2007; 39 (5): 874-878.

[47] F. Li, X. Tian, Y. Zhou, L. Zhu, B. Wang, M. Ding and H. Pang. Dysregulated expression of secretogranin III is involved in neurotoxin-induced dopaminergic neuron apoptosis. J. Neurosci. Res. 2012; 90 (12): 2237-2246.

[48] J. Jakobsson, M. Stridsberg, H. Zetterberg, K. Blennow, C. J. Ekman, A. G. Johansson et al. Decreased cerebrospinal fluid secretogranin II concentrations in severe forms of bipolar disorder. J. Psychiatry Neurosci. JPN. 2013; 38 (4): E21-E26.

[49] I. Begcevic, D. Brinc, A. P. Drabovich, I. Batruch, and E. P. Diamandis. Identification of brain-enriched proteins in the cerebrospinal fluid proteome by LC-MS/MS profiling and mining of the Human Protein Atlas. Clin. Proteomics. 2016; 13: 11. 
[50] Y. Fujita and T. Yamashita. The roles of RGMa-neogenin signaling in inflammation and angiogenesis. Inflamm. Regen. 2017; 37: 6.

[51] S. R. Krueger, G. P. Ghisu, P. Cenelli, T. P. Gschwend, T. Osterwalder, D. P. Wolfer and P. Sonderegger. Expression of neuroserpin, an inhibitor of tissue plasminogen activator, in the developing and adult nervous system of the mouse. J. Neurosci. Off. J. Soc. Neurosci. 1997; 17 (23): 8984-8996.

[52] T. W. Lee, V. W. K. Tsang, E. J. Loef, and N. P. Birch. Physiological and pathological functions of neuroserpin: Regulation of cellular responses through multiple mechanisms. Semin. Cell Dev. Biol. 2017; 62: 152-159.

[53] S. Caccia, S. Ricagno, and M. Bolognesi. Molecular bases of neuroserpin function and pathology. Biomol. Concepts. 2010; 1 (2): 117-130.

[54] T. Osterwalder, J. Contartese, E. T. Stoeckli, T. B. Kuhn, and P. Sonderegger. Neuroserpin, an axonally secreted serine protease inhibitor. EMBO J. 1996; 15 (12): 29442953.

[55] T. W. Lee, V. W. K. Tsang, and N. P. Birch. Physiological and pathological roles of tissue plasminogen activator and its inhibitor neuroserpin in the nervous system. Front. Cell. Neurosci. 2015; 9: 396.

[56] R. L. Davis, A. E. Shrimpton, P. D. Holohan, C. Bradshaw, D. Feiglin, G. H. Collins et al. Familial dementia caused by polymerization of mutant neuroserpin. Nature. 1999; 401 (6751): 376-379.

[57] E. Miranda, I. Macleod, M. J. Davies, J. Perez, K. Römisch, D. C. Crowther and D. A. Lomas. The intracellular accumulation of polymeric neuroserpin explains the severity of the dementia FENIB. Hum. Mol. Genet. 2008; 17 (11): 1527-1539.

[58] R. Noto, M. G. Santangelo, S. Ricagno, M. R. Mangione, M. Levantino, M. Pezzulo et al. The Tempered Polymerization of Human Neuroserpin. PLoS ONE. 2012; 7 (3): e32444.

[59] K. J. Kinghorn, D. C. Crowther, L. K. Sharp, C. Nerelius, R. L. Davis, H. T. Chang et al. Neuroserpin binds Abeta and is a neuroprotective component of amyloid plaques in Alzheimer disease. J. Biol. Chem. 2006; 281 (39): 29268-29277.

[60] A. Chiou, P. Hägglöf, A. Orte, A. Y. Chen, P. D. Dunne, D. Belorgy et al. Probing neuroserpin polymerization and interaction with amyloid-beta peptides using single molecule fluorescence. Biophys. J. 2009; 97 (8): 2306-2315.

[61] B. Subhadra, K. Schaller, and N. W. Seeds. Neuroserpin up-regulation in the Alzheimer's disease brain is associated with elevated thyroid hormone receptor- $\beta 1$ and $\mathrm{HuD}$ expression. Neurochem. Int. 2013; 63 (5): 476-481.

[62] T. Teesalu, A. Kulla, A. Simisker, V. Sirèn, D. A. Lawrence, T. Asser and A. Vaeri. Tissue plasminogen activator and neuroserpin are widely expressed in the human central nervous system. Thromb. Haemost. 2004; 92 (2): 358-368.

[63] M. Uhlén, L. Fagerberg, B. M. Hallström, C. Lindskg, P. Oksvold, A. Mardinoglu et al. Proteomics. Tissue-based map of the human proteome. Science. 2015; 347 (6220): 1260419.

[64] M. Schultzberg, M. Ambatsis, E. B. Samuelsson, K. Kristensson, and N. van Meirvenne. Spread of Trypanosoma brucei to the nervous system: early attack on circumventricular organs and sensory ganglia. J. Neurosci. Res. 1988; 21 (1): 56-61.

[65] O. V. Nikolskaia, Y. V. Kim, O. Kovbasnjuk, K. J. Kim, and D. J. Grab. Entry of Trypanosoma brucei gambiense into microvascular endothelial cells of the human bloodbrain barrier. Int. J. Parasitol. 2006; 36 (5): 513-519. 
[66] O. V. Nikolskaia, A. P. de A Lima, Y. V. Kim, J. D. Lonsdale-Ecces, T. Fukuma, J. Scharfstein and D. J. Grab. Blood-brain barrier traversal by African trypanosomes requires calcium signaling induced by parasite cysteine protease. J. Clin. Invest. 2006; 116 (10): 2739-2747.

[67] E. Bertrand, F. Serie, I. Kone, J. Rive, L. Compaore, L. Sentilhes and J. Philippe. Symptomatologie générale de la trypanosomiase humaine africaine au moment du dépistage. Méd. Afr. noire, 1973; 20 (4): 303-314.

[68] K. Urech, A. Neumayr, and J. Blum. Sleeping Sickness in Travelers - Do They Really Sleep? PLoS Negl. Trop. Dis. 2011; 5 (11): e1358.

[69] D. Malamud. Saliva as a diagnostic fluid. Dent. Clin. North Am. 2011; 55 (1): 159-178.

[70] L. A. S. Nunes, S. Mussavira, and O. S. Bindhu. Clinical and diagnostic utility of saliva as a non-invasive diagnostic fluid.s spe systematic review. Biochem. Medica. 2015; 25 (2): 177-192.

[71] M. S. M. Al-Nimer, S. F. Mshatat, and H. I. Abdulla. Saliva $\alpha$-Synuclein and A High Extinction Coefficient Protein: A Novel Approach in Assessment Biomarkers of Parkinson's Disease. North Am. J. Med. Sci. 2014; 6 (12): 633-637.

[72] K. Fransen, T. Vermoesen, G. Beelaert, J. Menten, V. Hutse, K. Wouters et al. Using conventional HIV tests on oral fluid. J. Virol. Methods. 2013; 194 (1-2): 46-51.

[73] A. J. Yoon, B. Cheng, E. Philipone, R. Turner, and I. B. Lamster. Inflammatory biomarkers in saliva: assessing the strength of association of diabetes mellitus and periodontal status with the oral inflammatory burden. J. Clin. Periodontol. 2012, 39 (5): 434-440.

[74] M. B. Border, S. Schwartz, J. Carlson, C. F. Dibble, H. Kohlfarber, S. Offenbacher et al. Exploring salivary proteomes in edentulous patients with type 2 diabetes. Mol. Biosyst. 2012; 8 (4): 1304-1310.

[75] B. Zalewska-Szajda, S. Dariusz Szajda, N. Waszkiewicz, S. Chojnowska, E. Goscik, U. Lebkowska et al. Activity of N-acetyl- $\beta$-D-hexosaminidase in the saliva of children with type 1 diabetes. Postepy Hig. Med. Doswiadczalnej Online. 2013; 67: 996-999.

[76] J. W. Jenzano, N. F. Courts, D. A. Timko, and R. L. Lundblad. Levels of glandular kallikrein in whole saliva obtained from patients with solid tumors remote from the oral cavity. J. Dent. Res. 1986; 65 (1): 67-70.

[77] C. Streckfus, L. Bigler, M. Tucci, and J. T. Thigpen. A preliminary study of CA15-3, cerbB-2, epidermal growth factor receptor, cathepsin-D, and p53 in saliva among women with breast carcinoma. Cancer Invest. 2000; 18 (2): 101-109.

[78] S. P. Robins. Collagen crosslinks in metabolic bone disease. Acta Orthop. Scand. Suppl. 1995; 266: 171-175.

[79] H. Mlcochova, R. Hezova, M. Stanik, and O. Slaby. Urine microRNAs as potential noninvasive biomarkers in urologic cancers. Urol. Oncol. 2014; 32 (1): 41.e1-9.

[80] V. P. Shichkin, A. D. Lon, L. G. Yugrinova, Y. A. Grinevich, O. B. Belova, N. M. Berezhnaya et al. TNF receptor p55 and IL-8(72) and IL-8(77) isoforms: blood and urine levels in breast cancer patients. J. Immunotoxicol. 2009; 6 (4): 235-242.

[81] H. Ghanbari, K. Ghanbari, I. Beheshti, M. Munzar, A. Vasauskas, and P. Averback. Biochemical assay for AD7C-NTP in urine as an Alzheimer's disease marker. J. Clin. Lab. Anal. 1998; 12 (5): 285-288.

[82] J. Connolly, A. Siderowf, C. M. Clark, D. Mu, and D. Pratico. F2 isoprostane levels in plasma and urine do not support increased lipid peroxidation in cognitively impaired 

21 (2): 83-86.

[83] Q. Wang, A. Fan, Y. Yuan, L. Chen, X. Guo, X. Huang and G. Huang. Role of Moesin in Advanced Glycation End Products-Induced Angiogenesis of Human Umbilical Vein Endothelial Cells. Sci. Rep. 2016; 6: 22749.

[84] M. S. Henning, P. Stiedl, D. S. Barry, R. Mcahon, S. G. Morham, D, Walsh and M. H. Naghavi. PDZD8 is a novel moesin-interacting cytoskeletal regulatory protein that suppresses infection by herpes simplex virus type 1. Virology. 2011; 415 (2): 114-121.

[85] E. R. Ferreira, A. Bonfim-Melo, E. M. Cordero, R. A. Mortara. ERM Proteins play distinct roles in cell invasion by extracellular amastigotes of Trypanosoma cruzi. Front Microbiol. 2017; 8: 2230.

[86] D. Pore and N. Gupta. Ezrin-Radixin-Moesin family proteins in the regulation of B cell immune response. Crit. Rev. Immunol. 2015; 35 (1): 15-31.

[87] C. Lagresle-Peyrou, S. Luce, F. Ouchani, T. S. Soheili, H. Sadek, M. Chouteau et al. Xlinked primary immunodeficiency associated with hemizygous mutations in the moesin (MSN) gene. J. Allergy Clin. Immunol. 2016; 138 (6): 1681-1689.

[88] Y. X. Chen, W. Chang, W. M. Wang, X. L. Yu, Y. M. Wang, M. J. Zhang and N. Chen. Role of Moesin in Renal Fibrosis. PLOS ONE. 2014, 9 (11): e112936.

[89] T. Kinoshita, N. Nohata, M. Fuse, T. Hanazawa, N. Kkkawa, L. Fujimura et al. Tumor suppressive microRNA-133a regulates novel targets: moesin contributes to cancer cell proliferation and invasion in head and neck squamous cell carcinoma. Biochem. Biophys. Res. Commun. 2012; 418 (2): 378-383.

[90] Y. Li, C.-X. Zhou, and Y. Gao. Moesin regulates the motility of oral cancer cells via MT1MMP and E-cadherin/p120-catenin adhesion complex. Oral Oncol. 2015; 51 (10): 935943.

[91] R. S. Peebles. The intelectins: a new link between the immune response to parasitic infections and allergic inflammation? Am. J. Physiol. - Lung Cell. Mol. Physiol. 2010; 298 (3): 288-289.

[92] D. A. Wesener, K. Wangkanont, R. McBride, X. Song, M. B. Kraft, H. L. Hodges et al. Recognition of Microbial Glycans by Human Intelectin. Nat. Struct. Mol. Biol. 2015; 22 (8): 603-610.

[93] J. K. Lee, J. Schnee, M. Pang, M. Wolfert, L. G. Baum, K. W. Moremen and M. Pierce. Human homologs of the Xenopus oocyte cortical granule lectin XL35. Glycobiology. 2001; 11 (1): 65-73.

[94] J. Yan, L. Xu, Y. Zhang, C. Zhang, C. Zhang, F. Zhao and L. Feng. Comparative genomic and phylogenetic analyses of the intelectin gene family: implications for their origin and evolution. Dev. Comp. Immunol. 2013; 41 (2): 189-199.

[95] A. D. Pemberton, P. A. Knight, J. Gamble, W. H. Coledge, J. K. Lee, M. Pierce and H. R. Miller. Innate $\mathrm{BALB} / \mathrm{c}$ enteric epithelial responses to Trichinella spiralis: inducible expression of a novel goblet cell lectin, intelectin-2, and its natural deletion in C57BL/10 mice. J. Immunol. Baltim. Md 1950. 2004; 173 (3): 1894-1901.

[96] R. Vitorino, M. J. Lobo, A. J. Ferrer-Correira, J. R. Dubin, K. B. Tomer, D. P. M. Domigues et al. Identification of human whole saliva protein components using proteomics. Proteomics. 2004; 4 (4): 1109-1115.

[97] E. Kaufman and I. B. Lamster. The diagnostic applications of saliva-a review. Crit. Rev. Oral Biol. Med. Off. Publ. Am. Assoc. Oral Biol. 2002; 13 (2): 197-212. 
895

896

897

898

899

900

901

902

903

904
[98] D. Esser, G. Alvarez-Llamas, M. P. de Vries, D. Weening, R. J. Vonk, and H. Roelofsen. Sample Stability and Protein Composition of Saliva: Implications for Its Use as a Diagnostic Fluid. Biomark. Insights. 2008; 3: 25-27.

[99] M. Gröschl. Données actuelles sur l'analyse hormonale salivaire. Ann. Biol. Clin. 2009; 67 (5): 493-504.

[100] J. A. Vizcaíno, A. Csordas, N. del-Toro, J. A. Dianes, J. Griss, I. Lavidas et al. 2016 update of the PRIDE database and its related tools. Nucleic Acids Res. 2016; 44 (D1): $447-$ 456. 
905 Table 1: Characteristics of the screening and protein quantification cohort

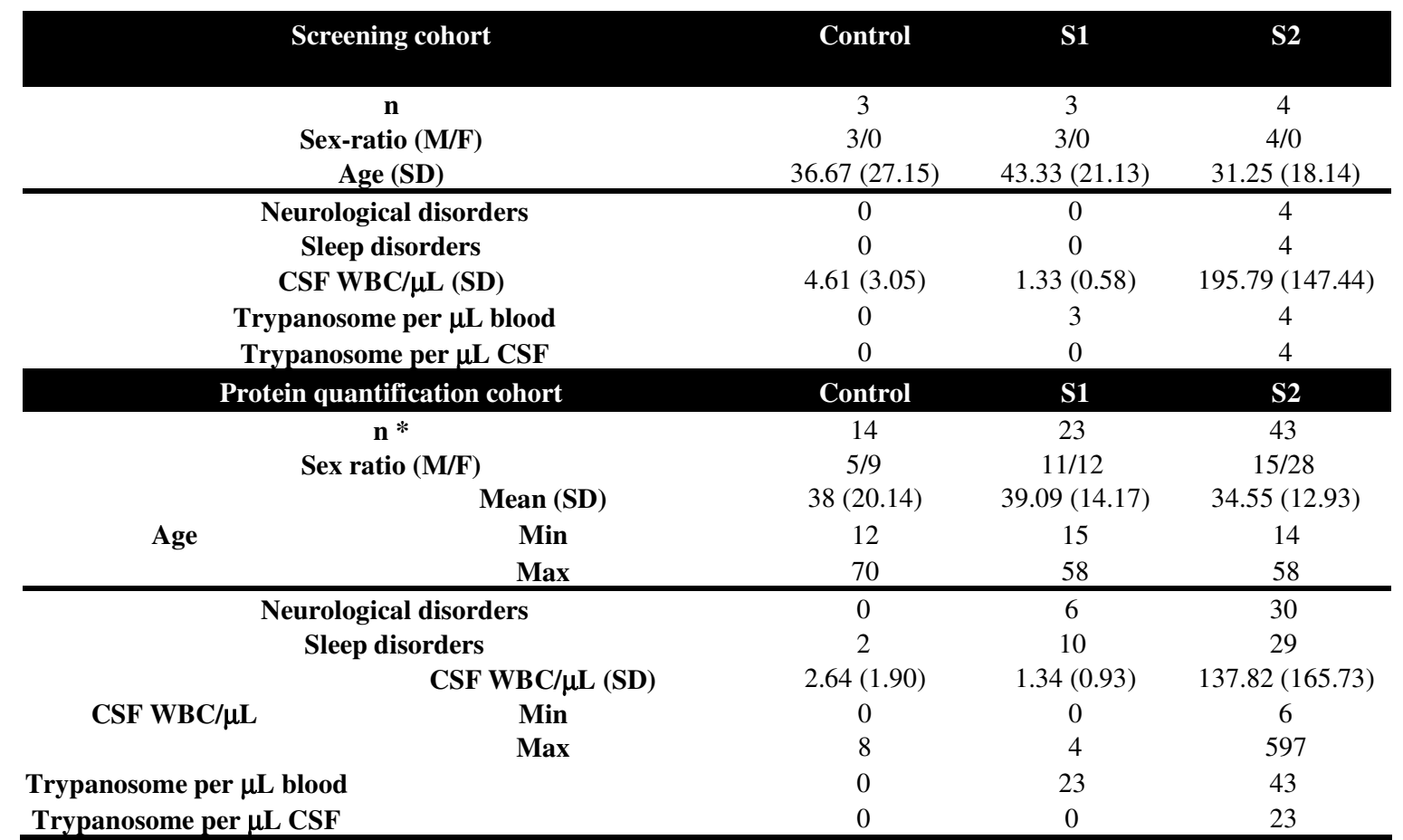

This table represents the epidemiological and biological data of 3 controls, 3 patients with stage 1

909 (S1) disease and 4 patients with stage 2 (S2) disease who constituted the screening cohort, as well

910 as the 14 controls, the 23 patients with S1 disease and the 43 patients with S2 disease enrolled in

911 protein quantification cohort. For urine and saliva analysis, some samples were not present in the 912 protein quantification cohort. *For urine $(\mathrm{n}=72)$ : 13 Controls, 21 S1 and 38 S2. For saliva $(n=$ 913 73): 13 controls, $22 \mathrm{~S} 1$ and $38 \mathrm{~S} 2$. 
915 Table 2: Top-10 best scored proteins identified in serum

\begin{tabular}{|c|c|c|c|c|c|c|c|}
\hline \multirow{2}{*}{ Accession } & \multirow{2}{*}{ Description } & \multirow{2}{*}{ Score } & \multirow{2}{*}{ ANOVA } & \multirow{2}{*}{$\begin{array}{l}\text { Max Fold } \\
\text { Change }\end{array}$} & \multicolumn{3}{|c|}{ Average normalized abundances } \\
\hline & & & & & Control & S1 & S2 \\
\hline CO3_HUMAN & Complement C3 & 8016.88 & 0.82 & 1.31 & $1.91 \mathrm{e}+007$ & $1.74 \mathrm{e}+007$ & $1.46 e+007$ \\
\hline A2MG_HUMAN & Alpha-2-macroglobulin & 5874.13 & 0.94 & 1.37 & $1.52 \mathrm{e}+007$ & $1.67 e+007$ & $1.22 \mathrm{e}+007$ \\
\hline VTDB_HUMAN & Vitamin D-binding protein & 5127.27 & 0.87 & 1.11 & $9.21 e+006$ & $8.29 e+006$ & $8.67 e+006$ \\
\hline APOB_HUMAN & Apolipoprotein B-100 & 4819.10 & 0.35 & 2.68 & $2.89 e+006$ & $1.08 \mathrm{e}+006$ & $1.08 \mathrm{e}+006$ \\
\hline TRFE_HUMAN & Serotransferrin & 4375.11 & 0.67 & 1.54 & $8.19 e+006$ & $1.26 \mathrm{e}+007$ & $1.18 \mathrm{e}+007$ \\
\hline CERU_HUMAN & Ceruloplasmin & 4249.73 & 0.18 & 1.47 & $3.09 e+007$ & $2.30 \mathrm{e}+007$ & $2.10 \mathrm{e}+007$ \\
\hline HPT_HUMAN & Haptoglobin & 3150.25 & 0.36 & 4.37 & $9.20 e+006$ & $1.34 \mathrm{e}+007$ & $4.02 e+007$ \\
\hline A1AT_HUMAN & Alpha-1-antitrypsin & 3085.22 & 0.63 & 1.22 & $3.80 e+007$ & $4.45 e+007$ & $3.64 \mathrm{e}+007$ \\
\hline IGHM_HUMAN & Ig mu chain $\mathrm{C}$ region & 2899.80 & 0.89 & 2.05 & $4.60 e+007$ & $3.58 \mathrm{e}+007$ & $2.25 e+007$ \\
\hline IGKC_HUMAN & Ig kappa chain $\mathrm{C}$ region & 2880.99 & 0.63 & 2.20 & $8.53 e+007$ & $7.25 e+007$ & $3.88 e+007$ \\
\hline IGHG1_HUMAN & Ig gamma- 1 chain $\mathrm{C}$ region & 2813.11 & 0.33 & 3.20 & $1.29 \mathrm{e}+007$ & $4.14 \mathrm{e}+007$ & $1.72 \mathrm{e}+007$ \\
\hline
\end{tabular}

916

917 S1: stage 1 disease; S2: stage 2 disease. Score: mascot protein score

918 
919 Table 3: Most notable proteins in the CSF with altered abundance levels between control, S1 and

$920 \quad$ S2 patients (classified by the increase in ANOVA $p$-value)

921

\begin{tabular}{|c|c|c|c|c|c|c|c|}
\hline \multirow{2}{*}{ Accession } & \multirow{2}{*}{ Description } & \multirow{2}{*}{ Score } & \multirow{2}{*}{ ANOVA } & \multirow{2}{*}{$\begin{array}{l}\text { Max Fold } \\
\text { Change }\end{array}$} & \multicolumn{3}{|c|}{ Average normalized abundances } \\
\hline & & & & & Control & S1 & S2 \\
\hline NEUS_HUMAN & Neuroserpin * & 33.73 & $2.61 \mathrm{e}-008$ & Infinity & $2.50 \mathrm{e}+004$ & $2.32 \mathrm{e}+004$ & 0.00 \\
\hline MCH_HUMAN & Pro $\mathrm{MCH}$ & 18.23 & $2.53 e-006$ & 51.23 & $2.67 e+004$ & $2.31 \mathrm{e}+004$ & 520.50 \\
\hline VGF_HUMAN & Neurosecretory protein VGF & 768.70 & $6.20 \mathrm{e}-006$ & 17.49 & $1.46 e+006$ & $1.59 e+006$ & $9.10 e+004$ \\
\hline NDRG2_HUMAN & Protein NDRG2 & 26.38 & $9.85 e-006$ & Infinity & $3.65 e+004$ & $2.53 e+004$ & 0.00 \\
\hline NEO1_HUMAN & Neogenin * & 27.68 & $3.82 \mathrm{e}-005$ & Infinity & $2.72 e+004$ & $2.17 e+004$ & 0.00 \\
\hline PTPRS_HUMAN & Receptor type tyrosine protein phosphatase $S$ & 28.48 & $4.39 e-005$ & Infinity & $2.31 \mathrm{e}+004$ & $1.55 e+004$ & 0.00 \\
\hline SCG2_HUMAN & Secretogranin $2 *$ & 732.53 & $5.45 e-005$ & 11.27 & $2.49 \mathrm{e}+006$ & $2.01 e+006$ & $2.21 \mathrm{e}+005$ \\
\hline NCAM2_HUMAN & Neural cell adhesion molecule 2 & 123.80 & $2.49 e-004$ & 12.57 & $1.50 \mathrm{e}+005$ & $1.43 e+005$ & $1.19 \mathrm{e}+004$ \\
\hline AT1B1_HUMAN & Sodium/potassium transporting ATPase subunit beta 1 & 37.94 & $2.62 \mathrm{e}-004$ & 6864.45 & 1361.14 & 2311.93 & 0.34 \\
\hline DHPR_HUMAN & Dihydropteridine reductase & 112.47 & $3.39 e-004$ & 212.16 & $2.41 \mathrm{e}+004$ & $2.52 \mathrm{e}+004$ & 118.73 \\
\hline NFASC_HUMAN & Neurofascin & 106.58 & $3.98 e-004$ & 19.75 & $4.44 e+004$ & $4.74 \mathrm{e}+004$ & 2400.82 \\
\hline SCG3_HUMAN & Secretogranin 3 & 1068.39 & $4.07 e-004$ & 9.94 & $1.20 \mathrm{e}+006$ & $1.46 \mathrm{e}+006$ & $1.47 e+005$ \\
\hline SCG1_HUMAN & Secretogranin 1 & 4373.28 & $4.41 \mathrm{e}-004$ & 6.14 & $1.59 e+007$ & $1.30 \mathrm{e}+007$ & $2.58 \mathrm{e}+006$ \\
\hline PEBP4_HUMAN & Phosphatidylethanolamine binding protein 4 & 23.40 & $4.51 \mathrm{e}-004$ & 151.57 & $3.44 e+004$ & $1.89 e+004$ & 227.04 \\
\hline PCDH9_HUMAN & Protocadherin 9 & 42.21 & $4.54 \mathrm{e}-004$ & 473.46 & $6.07 e+004$ & $6.17 e+004$ & 130.22 \\
\hline TICN3_HUMAN & Testican 3 & 111.74 & $1.24 \mathrm{e}-003$ & 5.13 & $3.32 e+004$ & $2.87 e+004$ & 6478.72 \\
\hline NRX3A_HUMAN & Neurexin 3 & 37.45 & $1.33 e-003$ & 745.63 & 4182.12 & 9806.72 & 13.15 \\
\hline PTMA_HUMAN & Prothymosin alpha & 78.55 & $1.40 \mathrm{e}-003$ & 38.11 & $1.07 e+005$ & $6.51 e+004$ & $2.48 \mathrm{e}+006$ \\
\hline PENK_HUMAN & Proenkephalin A & 268.45 & $2.12 \mathrm{e}-003$ & 4.34 & $4.07 e+006$ & $3.54 \mathrm{e}+006$ & $9.39 e+005$ \\
\hline COL12_HUMAN & Collectin 12 & 134.26 & $3.30 e-003$ & 7.21 & $1.18 \mathrm{e}+005$ & $7.12 \mathrm{e}+004$ & $1.64 \mathrm{e}+004$ \\
\hline SPON1_HUMAN & Spondin 1 & 77.80 & $3.35 e-003$ & 11.26 & $8.09 e+004$ & $4.53 e+004$ & 7181.93 \\
\hline CNTN2_HUMAN & Contactin 2 & 347.42 & $3.99 e-003$ & 78.73 & $6.75 e+004$ & $6.28 \mathrm{e}+004$ & 857.46 \\
\hline TICN2_HUMAN & Testican 2 & 119.88 & $6.92 e-003$ & 9.75 & $5.79 e+004$ & $3.79 e+004$ & 5938.73 \\
\hline NCAM1_HUMAN & Neural cell adhesion molecule 1 & 709.91 & $8.60 e-003$ & 4.76 & $4.33 e+005$ & $3.25 e+005$ & $9.09 e+004$ \\
\hline CSTN1_HUMAN & Calsyntenin 1 & 293.93 & $9.35 e-003$ & 28.52 & $1.17 e+005$ & $1.24 \mathrm{e}+005$ & 4346.68 \\
\hline CNTN1_HUMAN & Contactin 1 & 469.45 & 0.01 & 5.46 & $2.21 \mathrm{e}+005$ & $1.60 \mathrm{e}+005$ & $4.04 e+004$ \\
\hline CAD13_HUMAN & Cadherin 13 & 144.25 & 0.01 & 386.59 & $3.18 \mathrm{e}+004$ & $4.65 e+004$ & 120.35 \\
\hline TIMP2_HUMAN & Metalloproteinase inhibitor 2 & 135.16 & 0.01 & 7.69 & $2.31 \mathrm{e}+005$ & $1.47 e+005$ & $3.01 \mathrm{e}+004$ \\
\hline L1CAM_HUMAN & Neural cell adhesion molecule L1 & 67.55 & 0.01 & 8.76 & $1.97 e+004$ & $1.95 e+004$ & 2254.34 \\
\hline TETN_HUMAN & Tetranectin & 473.62 & 0.02 & 6.41 & $2.20 \mathrm{e}+005$ & $2.53 e+005$ & $3.95 e+004$ \\
\hline OMGP_HUMAN & Oligodendrocyte myelin glycoprotein & 296.85 & 0.02 & 3.60 & $3.26 e+005$ & $2.25 e+005$ & $9.03 e+004$ \\
\hline NEUM_HUMAN & Neuromodulin & 129.92 & 0.02 & 2.67 & $1.58 \mathrm{e}+005$ & $2.67 e+005$ & $9.99 e+004$ \\
\hline CBLN4_HUMAN & Cerebellin 4 & 24.53 & 0.02 & 2214.50 & 5630.78 & 4124.35 & 2.54 \\
\hline ECM1_HUMAN & Extracellular matrix protein 1 & 136.66 & 0.03 & 2.25 & $1.08 \mathrm{e}+006$ & $1.16 \mathrm{e}+006$ & $5.15 e+005$ \\
\hline PEBP1_HUMAN & Phosphatidylethanolamine binding protein 1 & 268.07 & 0.03 & 12.41 & $1.54 \mathrm{e}+005$ & $1.94 \mathrm{e}+005$ & $1.56 \mathrm{e}+004$ \\
\hline TICN1_HUMAN & Testican 1 & 124.56 & 0.05 & 11.39 & $5.19 e+004$ & $5.17 e+004$ & 4556.89 \\
\hline MIF_HUMAN & Macrophage migration inhibitory factor & 56.43 & 0.05 & 13.45 & $1.82 \mathrm{e}+004$ & $2.73 e+004$ & 2031.17 \\
\hline
\end{tabular}

923 All shown proteins passed thresholds of a fold change $\geq 2$ and a $p$-value $\leq 0.05$. Score: mascot

924 protein score. $*$ Protein quantified by ELISA. S1: stage 1 disease; S2: stage 2 disease. 
926 Table 4: Most notable proteins in the urine with altered levels between control, S1 and S2

927 patients (classified by increase in ANOVA $p$-value)

\begin{tabular}{|c|c|c|c|c|c|c|c|}
\hline & \multirow{2}{*}{ Description } & \multirow{2}{*}{ Score } & \multirow{2}{*}{ ANOVA } & \multirow{2}{*}{$\begin{array}{c}\text { Fold } \\
\text { Change }\end{array}$} & \multicolumn{3}{|c|}{ Average normalized abundances } \\
\hline & & & & & Control & S1 & S2 \\
\hline P51688 & $\mathrm{N}$-sulphoglucosamine sulphohydrolase & 89.58 & $1.51 \mathrm{e}-004$ & Infinity & 0.00 & $5.23 e+004$ & 1856.39 \\
\hline P16870 & Carboxypeptidase E & 23.90 & $1.61 \mathrm{e}-004$ & Infinity & 0.00 & $2.06 e+004$ & 8488.37 \\
\hline P25774 & Cathepsin S & 151.85 & $5.80 \mathrm{e}-003$ & 371.97 & 37.12 & $1.38 \mathrm{e}+004$ & 621.63 \\
\hline P26038 & Moesin * & 319.43 & $9.38 \mathrm{e}-003$ & 47.11 & 1511.77 & $7.12 \mathrm{e}+004$ & $1.57 e+004$ \\
\hline P59190 & Ras-related protein Rab-15 & 47.97 & 0.02 & Infinity & 0.00 & $1.74 \mathrm{e}+005$ & 2088.10 \\
\hline P29622 & Kallistatin & 120.72 & 0.02 & 170.86 & 5936.72 & $4.28 \mathrm{e}+004$ & 250.56 \\
\hline Q9H8L6 & Multimerin 2 & 52.32 & 0.05 & Infinity & 0.00 & 8618.93 & $4.37 e+004$ \\
\hline P02766 & Transthyretin & 78.07 & 0.05 & 17.94 & $1.36 \mathrm{e}+004$ & $1.42 e+005$ & $2.44 e+005$ \\
\hline
\end{tabular}

928

929

930 All shown proteins passed thresholds of a fold change $\geq 2$ and a $p$-value $\leq 0.05$. Score: mascot

931 protein score. * Protein quantified by ELISA. S1: stage 1 disease; S2: stage 2 disease.

932 
933 Table 5: Most notable proteins in the saliva with altered levels between control, S1 and S2

934 patients (classified by increase in ANOVA $p$-value)

935

\begin{tabular}{|c|c|c|c|c|c|c|c|}
\hline \multirow{2}{*}{ Accession } & \multirow{2}{*}{ Description } & \multirow{2}{*}{ Score } & \multirow{2}{*}{ ANOVA } & \multirow{2}{*}{$\begin{array}{c}\text { Fold } \\
\text { Change }\end{array}$} & \multicolumn{3}{|c|}{ Average normalized abundances } \\
\hline & & & & & Control & S1 & S2 \\
\hline P19878 & Neutrophil cytosol factor 2 & 26.41 & $1.21 \mathrm{e}-005$ & Infinity & 0.00 & 1207.94 & 8375.66 \\
\hline Q8WWU7 & Intelectin $2 *$ & 44.75 & $1.23 e-004$ & 120.23 & $3.11 \mathrm{e}+004$ & 258.69 & 350.60 \\
\hline Q15643 & Thyroid receptor-interacting protein 11 & 25.42 & $3.24 \mathrm{e}-004$ & Infinity & 0.00 & 0.00 & $1.06 \mathrm{e}+005$ \\
\hline P22392 & Nucleoside diphosphate kinase B & 36.48 & $1.87 e-003$ & 7.52 & $2.34 \mathrm{e}+004$ & $4.61 e+004$ & $1.76 \mathrm{e}+005$ \\
\hline Q04446 & 1,4-alpha-glucan-branching enzyme & 40.31 & 0.01 & 28.76 & 515.25 & 7843.70 & $1.48 \mathrm{e}+004$ \\
\hline P35241 & Radixin & 357.98 & 0.02 & 2.48 & $3.30 e+005$ & $3.79 e+005$ & $8.19 e+005$ \\
\hline P27348 & 14-3-3 protein theta & 106.60 & 0.02 & 11.21 & 2444.76 & $1.19 e+004$ & $2.74 \mathrm{e}+004$ \\
\hline Q04323 & UBX domain-containing protein 1 & 101.23 & 0.02 & 408.77 & 27.88 & 5286.01 & $1.14 \mathrm{e}+004$ \\
\hline P49913 & Cathelicidin antimicrobial peptide & 93.06 & 0.02 & 13.27 & $1.99 e+004$ & $3.28 \mathrm{e}+004$ & $2.65 e+005$ \\
\hline 000602 & Ficolin-1 & 84.63 & 0.02 & 43.65 & 620.60 & 1512.69 & $2.71 \mathrm{e}+004$ \\
\hline Q9BQI0 & Allograft inflammatory factor 1-like & 41.75 & 0.02 & Infinity & 0.00 & 914.27 & 7081.79 \\
\hline P02753 & Retinol-binding protein 4 & 24.27 & 0.02 & 3.59 & $2.92 \mathrm{e}+004$ & $3.97 e+004$ & $1.05 e+005$ \\
\hline 060437 & Periplakin & 353.95 & 0.02 & 16.22 & 6164.29 & $1.30 \mathrm{e}+004$ & $1.00 \mathrm{e}+005$ \\
\hline Q9HC84 & Mucin-5B & 2457.44 & 0.03 & 11.30 & $2.98 \mathrm{e}+007$ & $2.64 \mathrm{e}+006$ & $5.98 \mathrm{e}+006$ \\
\hline P05120 & Plasminogen activator inhibitor 2 & 255.32 & 0.03 & 25.13 & 2266.87 & $3.00 e+004$ & $5.70 e+004$ \\
\hline P62136 & $\begin{array}{c}\text { Serine/threonine-protein phosphatase PP1-alpha } \\
\text { catalytic subunit }\end{array}$ & 130.27 & 0.03 & 23.02 & 1150.30 & $1.80 e+004$ & $2.65 e+004$ \\
\hline Q15631 & Translin & 49.17 & 0.03 & 20.39 & 722.18 & 2713.99 & $1.47 e+004$ \\
\hline P51888 & Prolargin & 22.23 & 0.03 & 17.73 & 3887.41 & $2.59 \mathrm{e}+004$ & $6.89 e+004$ \\
\hline Q13813 & Spectrin alpha chain, non-erythrocytic 1 & 257.23 & 0.04 & 11.90 & 2035.25 & 4051.54 & $2.42 \mathrm{e}+004$ \\
\hline P99999 & Cytochrome c & 231.53 & 0.04 & 4.55 & $2.80 \mathrm{e}+004$ & $4.21 e+004$ & $1.27 e+005$ \\
\hline P04632 & Calpain small subunit 1 & 220.74 & 0.04 & 5.69 & 9299.74 & $2.29 e+004$ & $5.29 e+004$ \\
\hline P31997 & $\begin{array}{l}\text { Carcinoembryonic antigen-related cell adhesion } \\
\text { molecule } 8\end{array}$ & 60.26 & 0.04 & 26.63 & 3450.76 & $1.15 e+004$ & $9.19 \mathrm{e}+004$ \\
\hline P30153 & $\begin{array}{l}\text { Serine/threonine-protein phosphatase } 2 \mathrm{~A} 65 \mathrm{kDa} \\
\text { regulatory subunit A alpha isoform }\end{array}$ & 52.04 & 0.04 & 6.29 & 1660.25 & 6513.70 & $1.04 e+004$ \\
\hline Q15907 & Ras-related protein Rab-11B & 43.85 & 0.04 & 6.84 & 4755.71 & $2.47 e+004$ & $3.25 e+004$ \\
\hline
\end{tabular}

936

937 All shown proteins passed thresholds of a fold change $\geq 2$ and a $p$-value $\leq 0.05$. Score: mascot

938 protein score. * Protein quantified by ELISA, S1: stage 1 disease; S2: stage 2 disease. 
Serum

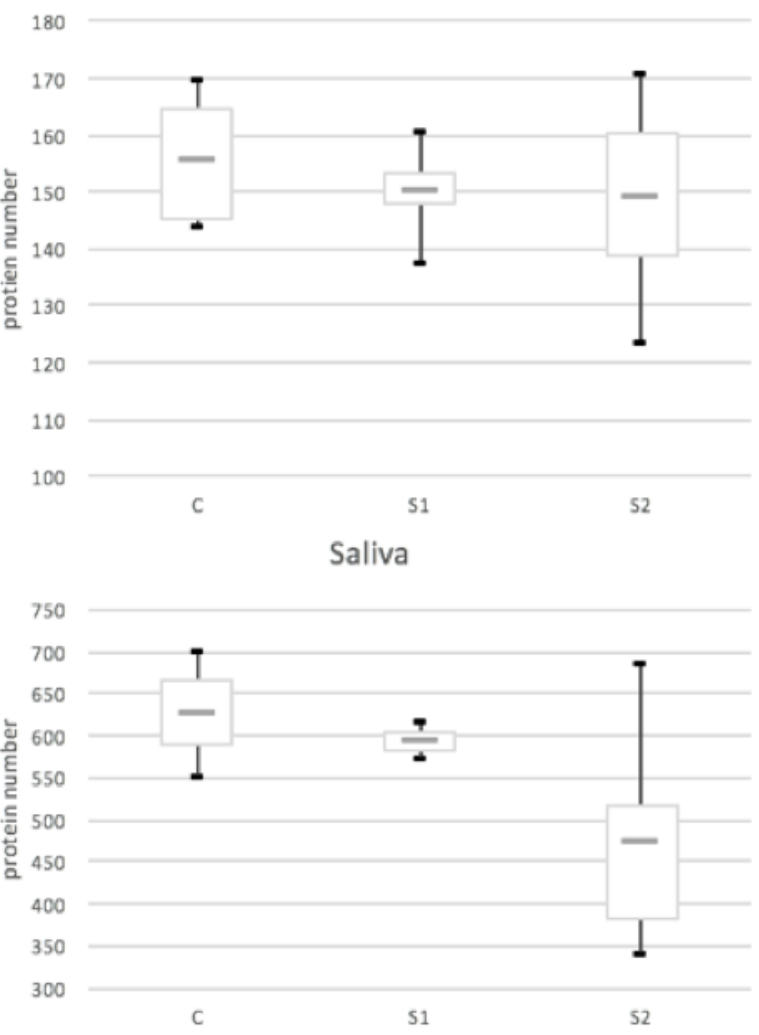

CSF
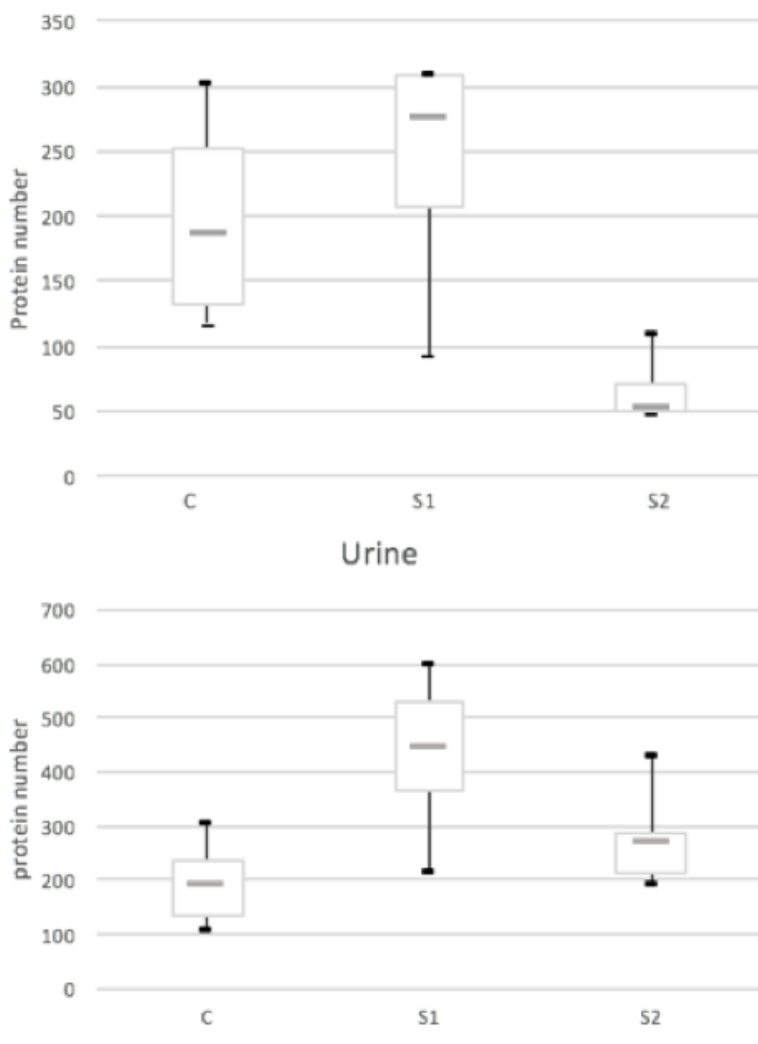


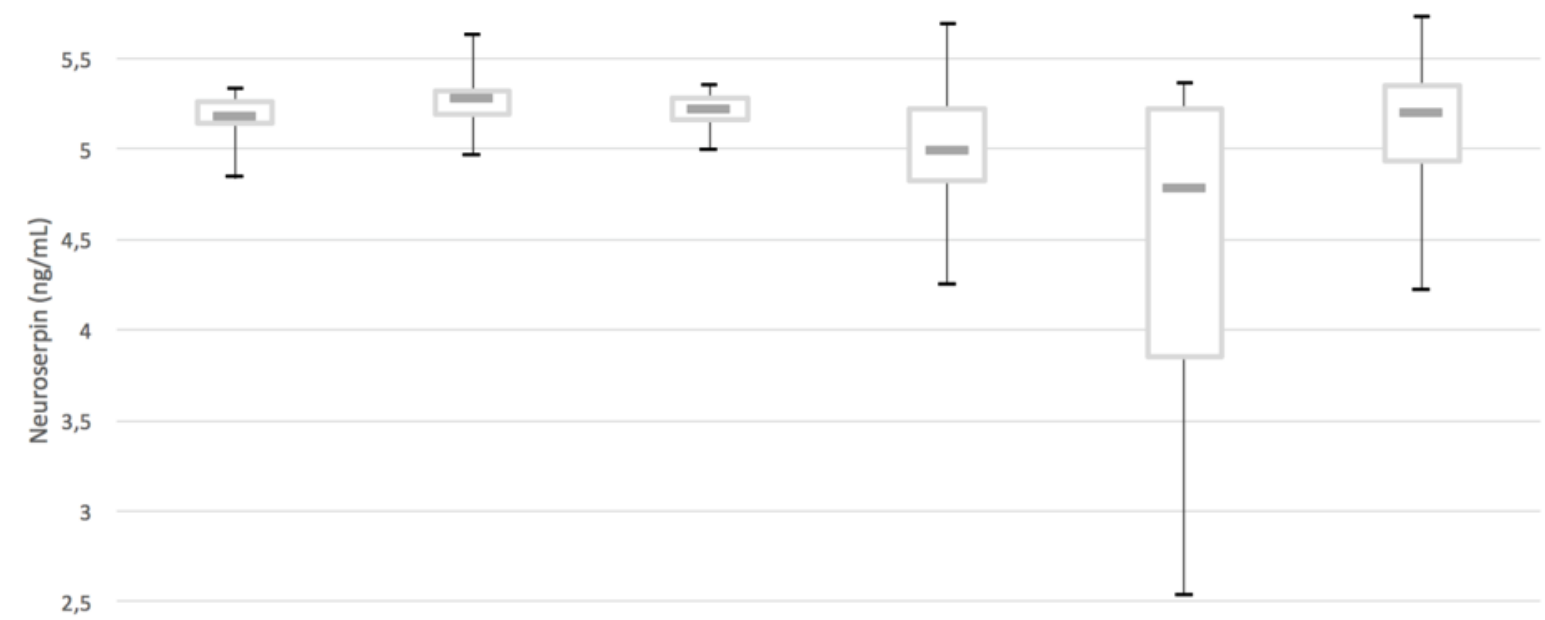

2 


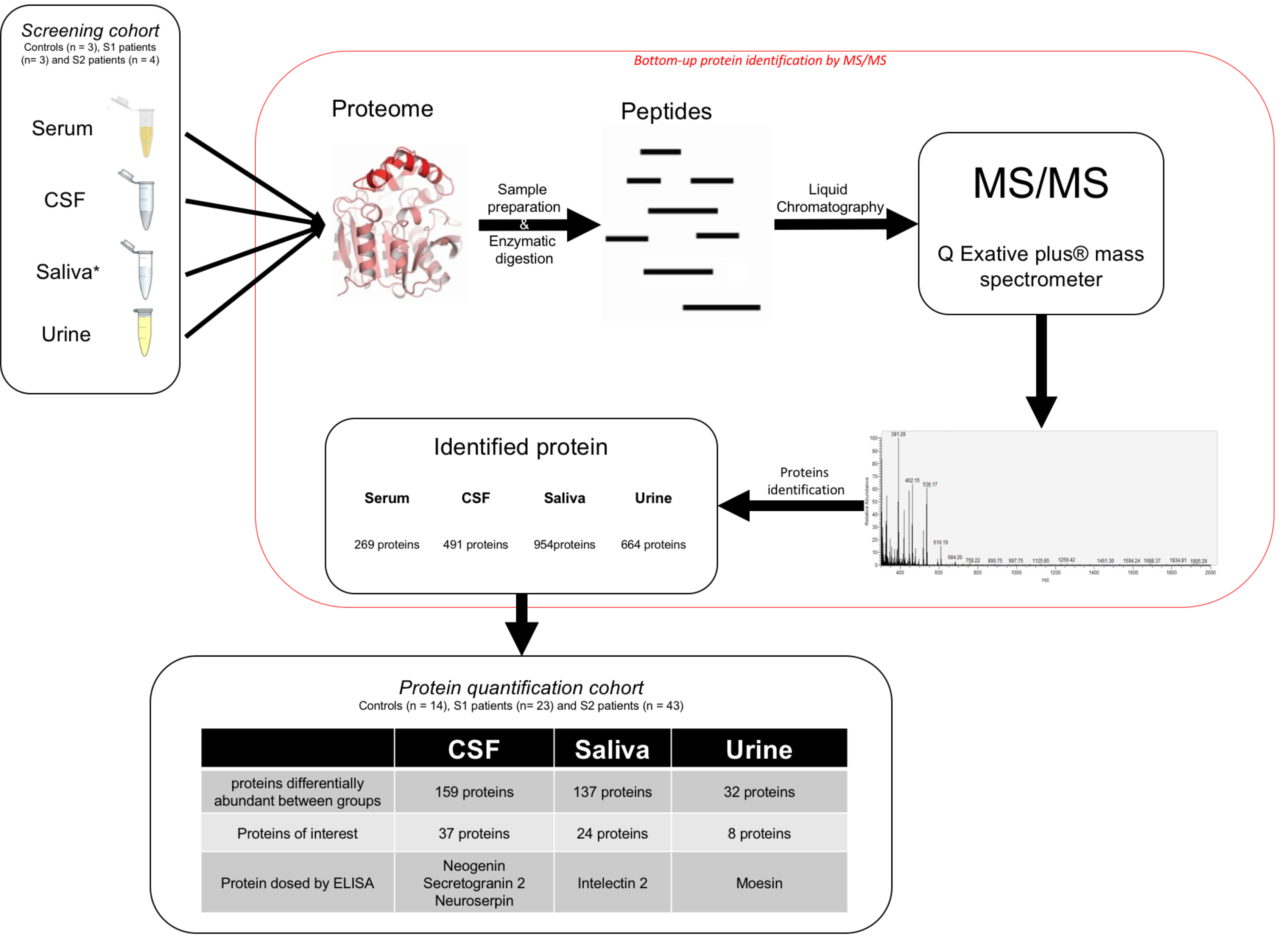

